\title{
JUAN DELGADO, FRANCISCO ORTEGA DELGADO Y EL MONUMENTO DE SEMANA SANTA DE LA CATEDRAL OVETENSE (1731-1740): FULGORES DEL BARROCO MADRILEÑO EN PROVINCIAS
}

\author{
JAVIER GONZÁLEZ SANTOS ${ }^{1}$ \\ Universidad de Oviedo
}

\begin{abstract}
La localización de una reproducción fotográfica del diseño original del monumento de Semana Santa de la catedral de Oviedo (en paradero desconocido desde 1924) nos permite trazar la historia de este desaparecido altar de perspectiva y bastidores pintados. Concebido por el pintor madrileño Francisco Ortega Delgado en 1732 y consagrado en 1740, fue destruido en 1903. La investigación desvela otros datos desconocidos, como la participación del pintor madrileño Juan Delgado en 1731 y el diseño de un altar gótico en 1903 para reemplazarlo.

Palabras clave: monumento de Semana Santa. Pintores: Juan Delgado Durán; Francisco Ortega Delgado; Ignacio Abarca Valdés; Francisco Martínez Bustamante; Manuel Montesinos Estellés; Ramón Romea y Ezquerra; Senén Rivero González-Rúa. Diletantes: Cosme Bernardo de Palacio; Pedro González Rivera.
\end{abstract}

\section{JUAN DELGADO, FRANCISCO ORTEGA DELGADO, AND THE HOLY WEEK MONUMENT OF OVIEDO CATHEDRAL (1731-1740): PROVINCIAL SPLENDOURS OF THE MADRID BAROQUE}

The discovery of a photograph of the original drawing (lost since 1924) of Oviedo Cathedral's Holy Week monument allows us to trace its intricate history. Created by the madrileño painter Francisco Ortega Delgado in 1732, the altar of painted perspective on stretch canvas was consecrated in 1740 and destroyed in 1903. Our research sheds light on previously unknown historical facts, such as the involvement of the painter Juan Delgado in 1731, as well as on the drawings of a new altar in the Gothic style to replace the eighteenth-century original.

Key words: Holy Week monument. Painters: Juan Delgado Durán; Francisco Ortega Delgado; Ignacio Abarca Valdés; Francisco Martínez Bustamante; Manuel Montesinos Estellés; Ramón Romea y Ezquerra; Senén Rivero GonzálezRúa. Dilettanti: Cosme Bernardo de Palacio; Pedro González Rivera.

Cómo citar este artículo / Citation: González Santos, Javier (2021) “Juan Delgado, Francisco Ortega Delgado y el monumento de Semana Santa de la catedral ovetense (1731-1740): fulgores del barroco madrileño en provincias”. En: Archivo Español de Arte, vol. 94, núm. 376, Madrid, pp. 365-386. https://doi.org/10.3989/aearte.2021.21

\section{Los monumentos eucarísticos de la catedral de Oviedo}

En marzo de 1731, la catedral de Oviedo tomó la determinación de sustituir el monumento de Semana Santa que en 1661-1665 habían construido Ignacio del Cajigal y José de Huici por otro nuevo, acorde con el gusto y ceremonial imperantes. El propósito, sin embargo, no se haría realidad hasta la Cuaresma de 1740.

\footnotetext{
${ }^{1}$ jgonzalez@uniovi.es / ORCID iD: https://orcid.org/0000-0002-3361-619X
} 
No era la primera vez que la catedral renovaba su altar eucarístico. En 1612-1613, sufragado por el obispo Juan Álvarez de Caldas (1605-1612), ${ }^{2}$ Juan Ducete Díez (Toro, 1549-1613) había erigido el primero. ${ }^{3}$ Demediado el siglo, su estructura clasicista resultaría anticuada, lo que unido al deterioro haría recomendable su reemplazo. Acordado en 1659, solo se pudo culminar en 1665 y en su construcción, tan problemática como dilatada, estuvieron comprometidos dos prelados (Bernardo Caballero de Paredes y Diego Riquelme de Quirós) y los artistas locales más cualificados: el escultor Luis Fernández de la Vega (Llantones, Gijón, h. 1601-Oviedo, 1675) y los arquitectos Ignacio del Cajigal († Oviedo, 1666) y José de Huici e Ituren († Arbizu, Navarra, 1690). ${ }^{4}$ A diferencia del templete de Ducete, el nuevo monumento era un túmulo con un cuerpo central, donde se hallaba la cama o sepulcro, con dos altares a los lados, por el tipo de aquel que Francisco Rizi (1614-1685) concibió poco después para la iglesia primada, ${ }^{5}$ bien entendido que el monumento toledano fue un tinglado de lienzos sobre bastidores y el de Oviedo, una máquina de madera y talla.

\section{EI monumento dieciochista}

Su hechura coincidió con el renovador pontificado del asturiano Juan García Avello y Castrillón (Luarca, 1673-Oviedo, 1744), amigo del padre Feijoo y dedicatario del primer tomo de las Cartas eruditas y curiosas (Madrid, 1742). García Avello gobernó la diócesis desde 1730 y en esos tres lustros la catedral experimentó una transformación de cualificados vuelos merced a los pingües ingresos de un arbitrio que disfrutó entre 1726 y $1750 .{ }^{6}$ Entre otras cosas, la construcción y alhajado de la sacristía (1732-1734), la ampliación y fachada del claustro en 1733-1740, los retablos colaterales (1739-1741 y 1742), el más deslumbrante testimonio del barroco decorativo madrileño existente en Asturias, ${ }^{7}$ y los grandes órganos del coro. Fue en este contexto en el que se inscribió la comisión del nuevo altar eucarístico [figs. 1 y 8].

El primer Diccionario de la lengua (editado entonces) define monumento como el "túmulo, altar o aparato que el Jueves Santo se forma en las Iglesias, colocando en él, en una arquita à modo de sepulchro, la segunda hostia que se consagra en la Missa de aquel día para reservarla hasta los Oficios del Viernes Santo, en que se consume. Hácese en memoria del tiempo que Nuestro Redentor Jesu Christo estuvo en el sepulchro". ${ }^{8}$

Ante esta periódica capilla ardiente se congregan los católicos para celebrar el culto de las Cuarenta Horas, exposición ritual del Santísimo Sacramento. ${ }^{9}$

\footnotetext{
${ }^{2}$ A Álvarez de Caldas (Caldas de Luna, León, 1542-Ávila, 1615) debió la diócesis ovetense la implantación de los decretos tridentinos y unas Constituciones sinodales en 1608 (Risco, 1795: 141-143).

${ }^{3}$ González Santos, 1997: 97-100 y 134-137.

${ }^{4}$ Ramallo, 1983: 31, 47 y 58; 1985: 156, 180-181, 207, 224-225 y 239; 1991: 65-67, n. os 39 y 40; 1999: 174, 175 y 179; 2011: 669 у 673 .

${ }^{5}$ El dibujo se conserva en los Uffizi (Lamas, 2016: 208-209, cat. 96). Confróntese con el atribuido a Rizi del Museo Casa de la Moneda (inv. 330. Durán, 1980: $56-57$ y 152, n. ${ }^{\circ} 64$ ), proyecto de monumento para un convento mercedario, no catedralicio. Nicolau, 1989. López Conde, 2011: 712-713. Otro monumento coetáneo fue el de la capilla del Alcázar Real, diseñado por Sebastián de Herrera Barnuevo y construido por Pedro de la Torre en 1668 (Fernández Bayton, 1975: I, 381-382, ord. 85. Barrio / Martín, 1981).

${ }^{6}$ Concedido por Felipe V (decreto de 22-X-1726) de un real por cada fanega de sal vendida en el principado de Asturias para reparar la torre de la catedral dañada por un rayo el 13 de diciembre de 1723. Ramallo, 1985: 62; $1999: 197$. Madrid, 1998: 128-131, nota 227. García Menéndez, 2008: 564, nota 3.

${ }^{7}$ Para los colaterales, diseñados por Diego de Villanueva, ensamblados por Toribio de Nava Riestra (Vega de Poja, Siero, 1687-Pola de Siero, 1748) y Manuel de Pedredo Vigil (Feleches, Siero, 1675-Oviedo, 1743), e imágenes de Juan de Villanueva y Barbales, véase García Menéndez, 2007, 2009, 2010 y 2011.

${ }^{8}$ Autoridades, 1734: 603. Monumento significaba también sepulcro o tumba. Interián, 1730/1782: I, 347-348, 358359,462 y 470

${ }^{9}$ El prolijo ceremonial, en Zuazo, 1753: IV, § VI-VIII, 344 y siguientes, e Irayzos, 1757: IV, cap. IV, § I-IV, 201-215. López Conde, 2011.
} 


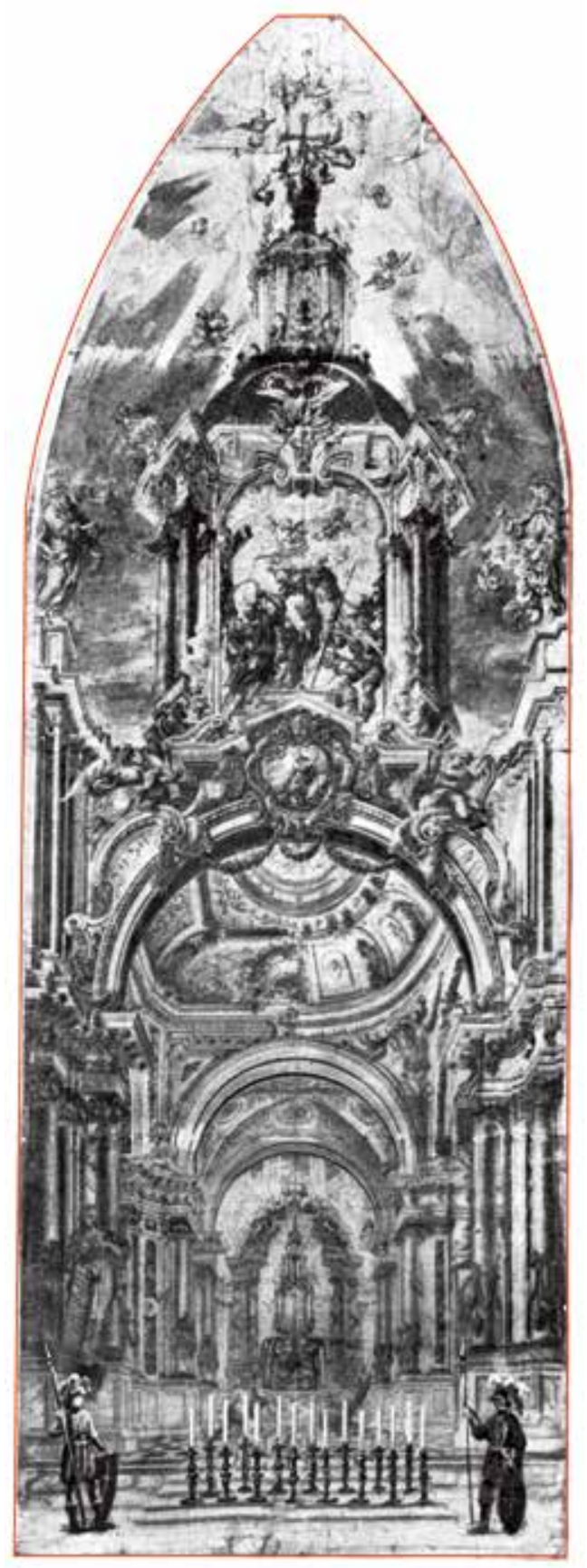

Fig. 1. Francisco Ortega, reproducción del diseño del Monumento de Semana Santa de la catedral de Oviedo, 1732 (con añadidos de Adolfo de Sandoval, 1924). En La Estrella del Mar (1924, p. 197).

\section{El malogrado proyecto de Juan Delgado}

Fue a mediados de marzo de 1731, en plena Cuaresma, cuando los capitulares advirtieron "la necesidad que auía de un buen Monumento", inquietud suscitada por el montaje de aquel de $1665 .{ }^{10}$ Acordaron diputar al arcediano de Villaviciosa, José Ángel de Mier (por entonces en Ma-

${ }_{10}$ De 1732-1734, tenemos el dato de lo que costaba armarlo: 6784 maravedís. Libro de quentas de la fáurica de esta S. Yglesia Cathedral. Año de 1713, Archivo Histórico Nacional (AHN): Clero, libro 9172, f. 169v. 
drid) para que buscase artífice y averiguar el coste. ${ }^{11} \mathrm{~A}$ finales de julio, el arcediano "presentó una planta para un monumento" de "pinturas" presupuestado en 22.000 reales, importe que no incluía transporte ni montaje. ${ }^{12}$ El cabildo decidió iniciar el proceso, condicionándolo a los caudales de la fábrica. ${ }^{13} \mathrm{Y}$ como a cuenta de las medias anatas ${ }^{14}$ de 1732 estimaba contar con 27.000 reales, resolvió formalizar el encargo. ${ }^{15} \mathrm{Al}$ efecto, extendió un poder a José de Posada Arenas, "residente en Madrid", para escriturar "con don Juan Delgado, pintor y maestro en dicha arte", ${ }^{16}$ y contratar "la formazión, hechura y pinturas de vn Monumento, con sus lienzos y más materiales". ${ }^{17}$

No conocemos ese contrato, pero el agente comunicó al cabildo que había sido concertado y que Delgado pedía un anticipo de 6000 reales "para lienzos y más prevenciones", que le fue remitido. ${ }^{18}$ Así las cosas, dos meses más tarde, el 20 de diciembre de 1731, el arcediano de Villaviciosa informaba que "el maestro con quien estaba ajustado hacer el Monumento... auía muerto. Y que le escribían se hallaba allí otro mozo de abilidad que auía trabajado en Segobia y en el convento de los padres de el Paular; y que este vendría aquí hacerle si el cavildo gustase de eso". Antes de dar cualquier paso, los canónigos se avinieron en recabar información "sobre la abilidad de dicho sujeto". ${ }^{19}$

En efecto: el 1 de diciembre de 1731 se asentaba en la parroquia madrileña de San Martín la defunción de Juan Delgado, fallecido el mismo día. ${ }^{20}$ La actividad profesional de Juan Francisco José Delgado Durán (Madrid, h. 1671/1675-1731) es conocida a partir de 1695. Era hijo de Juan Felipe Delgado García (Madrid, 1646-1721), "profesor del Arte de la Pintura", con quien a veces fue confundido. ${ }^{21}$ Juan Delgado fue maestro de Bernabé García (Madrid, 1679-1731) y Juan García de Miranda (Madrid, 1677-1749), ${ }^{22}$ con cuya familia mantuvo buena relación hasta 1724, cuando se enconó el pleito de los tasadores. ${ }^{23}$ De 1775 existe un interesante documento biográfico de los Delgado escrito por Antonio Miranda García (Madrid, 1710-Avilés, 1786), otro alumno suyo. ${ }^{24}$

Delgado Durán fue un acreditado tramoyista. Intervino en el coliseo del Buen Retiro en la comedia Angélica y Medoro de Antonio de Zamora, estrenada el 7 de abril 1722 para las bodas del príncipe de Asturias, Luis de Borbón con Luisa Isabel de Orléans. Con este motivo, junto con José de Yélamos decoró la Casa de la Panadería. ${ }^{25}$ También compuso la escenografía concebida por

${ }^{11}$ Cabildo de 15-III-1731, Archivo de la Catedral de Oviedo (ACO): Acuerdos capitulares, 47, f. $25 \mathrm{r}$.

${ }_{12}$ Cabildo de 27-VII-1731, ACO: Acuerdos capitulares, 47, f. 84rv.

${ }_{13}$ Cabildo de 21-VIII-1731, ACO: Acuerdos capitulares, 47, f. 87v.

${ }^{14}$ Media anata es el derecho pagado al ingreso de cualquier beneficio eclesiástico, pensión o empleo secular, correspondiente a la mitad de lo que produce en un año (DRAE).

15 Ángulo de 1-IX-1731, ACO: Acuerdos capitulares, 47, f. 91v.

${ }^{16}$ Cabildo de 3-IX-1731, Aco: Acuerdos capitulares, 47, f. 92r. Ramallo, 1985: 44, nota 8.

${ }^{17}$ Poder, Oviedo, 3-IX-1731, Archivo Histórico de Asturias (AHA): caja 7683, f. [110].

18 Cabildo de 6-X-1731, Aco: Acuerdos capitulares, 47, f. 97v. Ramallo, 1999: 213b. Registramos sin éxito las escrituras de Domingo Munilla y Zuazo posteriores al 3-IX-1731 (Archivo Histórico de Protocolos de Madrid, AHPM: leg. 14226), ante quien Delgado y su esposa otorgaron poder para testar el 14-XI-1722 (leg. 14224, f. 194).

19 ACO: Acuerdos capitulares, 47, f. 131v. Ramallo, 1999: 213-214a, nota 99.

${ }^{20}$ Archivo Histórico Diocesano de Madrid (AHDM): San Martín. Defunciones, libro 16, f. 34r. Aterido, 2015: 265; 2015a: 93.

${ }^{21}$ Por ejemplo, Agulló, 1981: 70-71 y 74; 1996: 27. Lo conocido de su vida, en Aterido, 2015a: 82-87. Para Delgado Durán, Ponz, 1776: 7. a división, § 3. Ceán, 1800: II, 7-8, 89, 169, 284, y vI, 273; 2016: 437-438. Agulló, 1981: 218-219; 1994: 44 y 147. Montaner, 1988: 392-393, 402 y 403, láms. VII y viII. Barrio, 2003. Pérez Sánchez, 2010: $407 a$ y $409 b$. González Santos, 2014: 47, figs. 1 y 2. Aterido, 2015: 247, 248 y 249; 2015a: 87-93.

${ }^{22}$ Ceán, 1800: II, 161 y 169; 2016: 447 y 439. Jiménez Priego, 1982: 134-137. Delgado asistió al contrato matrimonial de Nicolás García de Miranda (Madrid, 12-XII-1713) e intervino en la tasación de las pinturas verificada al día siguiente, siendo testigo su padre Juan Felipe Delgado (Agulló, 1981: 91-93).

${ }_{23}$ Ceán, 1800: II, 170-171, nota. Simón, 1947. Pérez Sánchez, 1985: 216, 225 y 226; 2010: 404 y $470 a$, nota 2. Aterido, 2015: 247-248.

${ }^{24}$ Secretaría General. Varios. 1775. Memorial del impresor D. Antonio Sanz al Marqués de Grimaldi, Archivo de la Real Academia de Bellas Artes de San Fernando (ARABASF): 5-62-8, ff. 71-72 y 69-70 (moderna). Fue redactado para la edición actualizada de El Parnaso de Palomino que pretendía el impresor Antonio Sanz. Úbeda, 2001: 55-56. Bassegoda, 2004: 102-105. García López, 2014: 111-112. Aterido, 2015: 214, 224, 234 (nota 119), 235 (nota 169), 243 y 294 (nota 20). Identifica al autor y lo publica González Santos, 2017.

${ }^{25}$ Barrio, 2003: 103. López / Varey, 2006: 22-27, 188, 202 y 206-207. Aterido, 2015a: 90. 
Pedro de Ribera para La hazaña mayor de Alcides de José de Cañizares en el Carnaval de $1723 .{ }^{26}$ Esta experiencia sería la que atrajo el interés del cabildo ovetense para confiarle la realización de un monumento de perspectiva.

\section{Francisco Ortega Delgado}

Aquel "mozo ${ }^{27}$ de abilidad" era Francisco Ortega Delgado, pero su nombre no se hizo expreso hasta el 10 de octubre de 1732. Antes, habían llegado noticias de su capacidad, que "no era tanta... para una obra como esta", por lo que se habló de tantear a "un maestro de mucha fama que ai en Madrid, aunque este sería más caro". Quién fuera, no se dice, pero atendiendo a su habilidad en pintura ilusionista podría tratarse de Juan Vicente de Ribera (Madrid, h. 1668-1736), si no aludían a Pedro de Ribera (Madrid, 1681-1742). Finalmente, los capitulares acordaron que se encargara "al maestro de Madrid" (Francisco Ortega) y supuesto "quiere hacer nueba planta y no arreglarse a la que hizo el otro maestro... que se avise... haga planta a su modo y que se le embíen las medidas de el sitio" y averigüe "el costo que podrá tener". ${ }^{28}$ El siguiente paso fue recuperar los seis mil reales anticipados a Juan Delgado. ${ }^{29}$

Francisco Ortega, nacido en Andújar (Jaén) en 1691 o 1692, fue "profesor de la pintura y vezino de esta Corte" ${ }^{30}$ y uno de aquellos designados por el Consejo de Castilla en 1724 para tasar pinturas. ${ }^{31}$ Poco se conoce de él. Ceán lo hizo discípulo de "su paisano Palomino". ${ }^{32}$ En 1731 reparó las bóvedas del coro, nave y transepto de la iglesia de la Merced Calzada de Madrid (pintadas por Antonio Pereda y Juan Fernández de Gandía en 1660-1661), firmó el Nacimiento de san Pedro Nolasco para el claustro de aquella casa y retocó otros. ${ }^{33}$ En la edición de las Noticias de los arquitectos de Llaguno, refiere que fue discípulo y asistente de Teodoro Ardemans (Madrid, 1661-1726) y que, especializado en ilusionismo arquitectónico y pintura decorativa, lo ayudó a "hacer las trazas del retablo de jaspes y bronces de S. Ildefonso" en la capilla del palacio de la Granja (Segovia). Y concluye que Ortega fue creado ayudante de trazador de las obras reales el 11 de febrero de 1729 por muerte de José Benito de Churriguera (Madrid, 1665-1725). ${ }^{34}$ Pero desde 1714 Ortega ya trabajaba con Palomino a las órdenes de Ardemans (maestro mayor de obras reales en 1702) ${ }^{35}$ en el salón de Grandes del Alcázar, en obras entre 1710 y 1721 y tasadas en $1723 .{ }^{36}$ Su habilidad como copista queda acreditada en un inventario de 1748, donde se cuentan varias a partir de originales de José Ribera, Guido Reni y Anton van Dyck, dos "ideas para los quadros del venerable padre [Simón de] Rojas, historiados", y otras pinturas originales, como dos floreros de azucenas y lirios o la Fábula de Latona, lo que da idea de su versatilidad y variedad de géneros cultivados. ${ }^{37}$

\footnotetext{
${ }^{26}$ Barrio, 2003: 103. López / Varey, 2006: 27-28, 209 y 221. Aterido, 2015a: 90. Hay edición de esta comedia (José de Cañizares: Las amazonas de España. La hazaña mayor de Alcides. Estudio y edición a cargo de Ignacio López Alemany. Madrid-Frankfurt: Iberoamérica-Vervuert, 2018).

${ }_{27}$ Mozo significa también célibe, soltero (Autoridades), precisamente, el estado civil del pintor.

${ }^{28}$ Cabildo de 4-II-1732, ACO: Acuerdos capitulares, 47, f. 141r.

${ }^{29}$ Cabildo de 7-VII-1732, ACO: Acuerdos capitulares, 47, f. 182v.

30 Agulló, 1994: 84-85. Aterido, 2015a: 209-212.

${ }^{31}$ Ceán, 1800: II, 171. Simón, 1944: 124-127. Aterido, 2015a: 210. Su nombramiento data de 1725 (Barrio, 1997: 102-103, con referencias de varias tasaciones entre 1728 y 1742, y designación por el marqués de Villena, el 28 de diciembre de 1734, junto a otros colegas para inventariar las pinturas salvadas del incendio del Alcázar). Bottineau, 1986: 488, nota 33, y 542. Aterido, 2015a: 211.

32 Ceán, 2016: 443.

${ }^{33}$ Demolido en 1837. Ceán, 1800: III, 280, IV, 64, y vI «Nota», 378-379; 1829: IV, 43; 2016: 442-443. Antes, Palomino, 1724a: vidas 106, § vIII, y 127; 1947: 925-926 y 959. Ponz, 1776: 2. división, § 35 y 38. Simón, 1947: 124 y 127. Barrio, 1997: 128-130.

${ }^{34}$ Llaguno / Ceán, 1829: Iv, 112-113 y nota 1. Aterido, 2015a: 210.

35 Ceán, 1800: I, 51. Blasco, 2013: 396. Aterido, 2015a: 210.

${ }^{36}$ Ya trabajaba allí en 1715. Bottineau, 1986: 449 y 488, nota 29. Aterido, 1995-1996: 135, nota 29; 2015a: 209.

37 Barrio, 2000.
} 
En diciembre de 1727 y enero siguiente, Ortega, "profesor del arte de pintura y arquitecto", había peritado los retablos colaterales de las Calatravas (Madrid), labrados por Juan de Villanueva y Barbales (Pola de Siero, 1681-Madrid, 1765).$^{38} \mathrm{La}$ amistad con este escultor asturiano podría tener algo que ver con su determinación de trabajar para la catedral de Oviedo.

Francisco Ortega murió soltero en Madrid, el 9 de agosto de 1747. ${ }^{39}$ Había testado el 29 de julio de 1735 y hecho un codicilo el 2 de septiembre de 1744: dejaba heredera a su hermana María, vecina de Andújar, y tenía en su compañía a Juan Bautista Christín, que acabaría disfrutando todas las estampas, borrones y enseres del taller. ${ }^{40}$

\section{El proyecto definitivo}

El 10 de octubre de 1732 se recibió en Oviedo la planta de Francisco Ortega y las condiciones: si él la realizaba no cobraría nada por ella, "pero en caso de que no se haga o la tome otro, será preciso pagársela bien, por el mucho trabaxo que ha tenido"; se brindaba a realizarla con "todos los materiales y pinturas" por cuarenta mil reales, y si el cabildo ponía "los vastidores y projeturas ${ }^{41}$ y madera que se necesite para todos ellos y sus figuras, lienzo y clauazón, de suerte que solo haia de ser de quenta de el maestro los colores y pintado de la obra", la haría por treinta y tres mil, "y que vendrá... a executarla y dará acabada para la Semana Santa de el año próximo de 1733". Los capitulares aplazaron la resolución hasta oír el dictamen de los "pintores y hombres inteligentes" de la ciudad y su parecer sobre cuál de las dos (esta o la de Delgado) "sea mejor en esta Santa Iglesia y sitio donde debe estar". ${ }^{4}$

Los consultores fueron Ignacio Abarca Valdés (Oviedo, 1668-1735) y Francisco Martínez Bustamante (Santander, 1680-Oviedo, 1745), los primeros pintores profesionales que contó Asturias. Los dos se habían formado en Madrid y practicaron el barroco decorativo por el estilo de Lucas Jordán, Antonio Palomino y epígonos de Juan Carreño, como Miguel Jacinto Meléndez (Oviedo, 1679-Madrid, 1734), precisamente, maestro de Bustamante. ${ }^{43}$ Ambos prefirieron la idea de Francisco Ortega, pero no se pusieron de acuerdo cuánto costaría materializarla. Abarca estimaba que unos seis mil reales y Bustamante, once mil. El primero tasó la planta en doce doblones (960 rs) si la catedral se quedaba con ella y si la restituía "se le podían dar de tres a quatro" (240-320 rs). Bustamante, en cambio, opinó que cincuenta doblones (4000 rs) y "de quatro a seis" (320-480 rs) si la devolvía. Además, se brindó a "sacar una copia... por seis doblones" (480 rs). Ante esta disparidad, el cabildo convocó a un tercero, Cosme Bernardo de Palacio, "que se dice ser inteligente en este arte", para que "revean y reconozcan dicha planta y sepan si están hechos cargo de ella y si la sabrán executar". En fin, se convino pedir al confesor del monasterio de la Encarnación de Madrid información "del costo que ha tenido... el Monumento de perspectiva... que se dice es de buen gusto". ${ }^{44}$ Aludía a aquel de madera e ilusionista construido en 1699-1700 por José Benito de Churriguera. ${ }^{45}$

${ }^{38}$ Mandato de 22-XII-1727, Informe de 10 y Recibo de 14-I-1728, AHN: leg. 7020, exp. 105. García Menéndez, 2008 : 473-503, cats. R1 y R2, y Corpus documental, LV, LVI y LVII. Parcialmente, en Bonet, 1962: 42.

39 AHDM: Santos Justo y Pastor. Difuntos, libro 19, f. 132. Barrio, 1997: 126, nota 17. Aterido 2015a: 212.

40 AHPM: leg. 16043, ff. 210-211. Publicado por Barrio, 1997: 117-118, 126-128 y 131-137. Aterido, 2015a: 211 y 212.

${ }^{41}$ Proyectura, "saliente del paramento de una pared... lo mismo que vuelo" (DRAE). Palomino, 1715: sub voce; 1947: 1160b. Terreros (1788: 234b): "la arquitectura, el perfil que descubre la salida, ó vuelo de la cornisa, ú otra cualquier moldura, fuera de la línea perpendicular, ó del bastidor que se pinta".

${ }^{42}$ Cabildo de 10-X-1732, ACO: Acuerdos capitulares, 47, ff. 207v-208r. Ramallo, 1999: 214, nota 100.

${ }_{43}$ Para estos pintores, González Santos, 2009: 290-294, cats. P5 у P34; 2018: 135-142, cats. P1 y P2.

44 Cabildo de 20-X-1732, ACO: Acuerdos capitulares, 47, f. 210v. Ramallo, 1985: 543.

45 Aterido, 1995. Fue contratado en 50.000 reales, pero por la respuesta sabemos que acabó costando 66.000 (Cabildo de 23-XII-1732, ACO: Acuerdos capitulares, 47, f. 225r). 
Cosme Bernardo de Palacio (h. 1685/1690-Oviedo, 1739) fue administrador de rentas provinciales, pintor aficionado y un modesto coleccionista avecindado en Oviedo alrededor de $1727 \mathrm{o}$ $1728 .{ }^{46}$ Los peritos opinaron que el monumento se podría hacer por veintidós mil reales, estando por cuenta del artista "solo los colores y la manifactura, y de la del cavildo, los lienzos, clavazón y madera". Si Francisco Ortega no estuviese de acuerdo, la catedral propuso que el escultor Manuel de Pedredo Vigil "y uno de los dos pintores" fueran a Madrid la próxima Semana Santa para que, "haciéndose cargo de medidas y más circunstancia, vean si se obligarán a executar dicha planta". También resolvió enviar el proyecto al apoderado que tenía en la corte "para que se informe por quánto podrá executarse, como también de lo que merezca el maestro que la hizo por su trabajo". ${ }^{47}$

La contestación de Francisco Ortega llegó al cabo de un mes: urgía al cabildo a que le pagara el diseño y resolviese cuanto antes si quería contar con él, "pues se le sigue... inconueniente en que se dilate esta resolución" ${ }^{48}$ De finales de noviembre de 1732 pasamos a agosto de 1733 , cuando Juan Manuel Delgado Marcos de Merlo, hijo de Juan Delgado, se brindó a poner por obra el plan de su padre por veintiocho mil reales. Se le agradeció el gesto, sin comprometerse hasta averiguar "la habilidad de dicho Delgado". 49

Pero el negocio no se resolvía y algunos canónigos se quejaban de la incapacidad de los comisionados para encontrar un artista a satisfacción. ${ }^{50}$ En febrero de 1734, Francisco Ortega apremiaba a la catedral a que le pagara el proyecto, ya que "por aora parece no se piensa en executarle". Aunque esta acordó aplazar la construcción del monumento "mientras que la fábrica no tenga fondos" y dar diez doblones (800 rs) al artista, ${ }^{51}$ veintiún meses después (octubre de 1735), Ortega seguía reclamando el importe de la traza. El cabildo se avino entonces, pero en seiscientos reales, porque "no la tasaron más los peritos de esta ciudad" y si no, que se quedase con ella. ${ }^{52}$

La inacción y disimulo fueron la tónica de los años siguientes. De aquella fecha, pasamos a diciembre de 1738 (tres años más tarde), cuando el arcediano de Villaviciosa, comisario de obra, pidió a sus colegas que retribuyeran a Francisco Ortega, porque "le molesta de continuo", amenazando con demandar a la catedral. Para no comprometer al arcediano, el cabildo le permitió ajustar con el pintor lo que convinieran por la idea, estimada por aquel en "algo más de los doze doblones [960 rs] que antes de aora se le ofrecieron", dejando abierta la posibilidad a que si "quiere bolber á tomarla, se le remitirá, y seis doblones [480 rs] por su trabajo". ${ }^{33}$ Pero esto no ocurrió y, finalmente, la catedral se quedó con el proyecto a la espera de mejor coyuntura. Y esta se presentó al poco, dos meses más tarde y de modo inesperado. En el cabildo del 6 de febrero de 1739, Joaquín de Velarde informó que "se halla residiendo en esta ciudad don Pedro Rivera, inteligente bastantemente en hacer pinturas de perspectiva, según lo dio á entender en el Coliseo ${ }^{54}$ que hizo estos días de muy buen luzimiento", y propuso que "sería conveniente tratar con él tocante á Monumento", mostrándole "la planta que... vino de Madrid..., pues, en vista de ella podrá con más facilidad dar su resolución y saber si puede o no hacerle, de cuyo modo se aorraría mucho dinero". Con arreglo a lo expuesto, los capitulares determinaron que Velarde y otro canónigo fueran a tratar con Rivera "en orden á lo referido". ${ }^{55} \mathrm{El}$ ansiado monumento, cuya gestación se venía arrastrando hacía ocho años, entraba en su fase decisiva.

${ }^{46}$ González Santos, 2019.

${ }^{47}$ Cabildo de 24-X-1732, Aco: Acuerdos capitulares, 47, f. 212r.

48 Cabildo de 24-XI-1732, ACO: Acuerdos capitulares, 47, f. 219r. Ramallo, 1985: 44, nota 8; 1999: 214, nota 100.

49 Cabildo de 7-VIII-1733, ACO: Acuerdos capitulares, 47, f. 290v. Para este pintor, Aterido, 2015: 234 (nota 119), 243, 265 y 280; 2015a: 93.

50 Cabildo de 8-I-1734, ACO: Acuerdos capitulares, 48, f. 42v.

${ }^{51}$ Cabildo de 12-II-1734, ACO: Acuerdos capitulares, 48, f. 50v. Ramallo, 1999: 214a.

${ }^{52}$ Cabildo de 3-X-1735, Aco: Acuerdos capitulares, 48, f. 269r.

${ }^{53}$ Cabildo de 2-XII-1738, ACO: Acuerdos capitulares, 50, f. 213v. Ramallo, 1999: 214, nota 101.

${ }_{54}$ Teatro, por antonomasia. El Coliseo fue uno de los corrales de comedias más famosos de Sevilla en el siglo XVII.

55 Cabildo de 6-II-1739, ACO: Acuerdos capitulares, 50, f. 228v. Ramallo creyó a Rivera "sevillano" (Ramallo, 1985: 43, nota 7; 1999: 214, nota 102). 


\section{Pedro Rivera, "inteligente en hacer pinturas de perspectiva"}

De este individuo (que no cabe confundir con el maestro mayor de Madrid) hay muchas incógnitas y pocas certezas. La sola mención en las actas capitulares da a entender que no era un artista profesional, sino un aficionado con dotes de tracista y escenógrafo. Podría tratarse de Pedro González Rivera, vecino de Oviedo, aunque ausente algún tiempo. Su condición hidalga no plantea dudas y los papeles siempre se refieren a él con el tratamiento de don y omitiendo el primer apellido, aunque él firmaba con los dos.

Su actividad artística solo está acreditada en Oviedo $^{56}$ y en tres momentos diferentes: 17391740,1741 y $1747-1749$. Aparte del monumento catedralicio, en el invierno de 1739 trabajó los decorados para las funciones de la casa de comedias del Fontán ${ }^{57}$ y en la primavera de 1741 remitió un diseño (porque quizás se hallaba fuera) para la caja del primer órgano catedralicio ${ }^{58} \mathrm{En}$ 1747-1748, nuevamente convocado por la catedral, tuvo a su cargo el cuidado o "sobreestanzia de la fábrica de la caja de el órgano que oy día se halla fenezida" y a punto de ser dorada. ${ }^{59}$ En ambos casos se trataba de la del órgano mayor o de la epístola, diseñada por el navarro José de Lesaca y construida por José Bernardo de la Meana (Oviedo, 1715-1790). ${ }^{60}$

De 1749 hay dos documentos que testimonian el crédito y opinión de hombre de gusto que Rivera gozaba en la ciudad. El primero corresponde a la tasación "en lo tocante á tapicería" de los bienes del señor Miguel Jerónimo de Isunza y Quintana Dueñas († Oviedo, 5 de enero), regente de la Audiencia de Asturias. ${ }^{61} \mathrm{Y}$ de junio de aquel año hay otro, más interesante si cabe y a cuyo otorgamiento estuvo presente, que se refiere a él como autor de las trazas ("formadas por D. ${ }^{\mathrm{n}}$ Pedro Riu. ${ }^{a}$, vezino de esta ciudad") de los retablos de San Francisco de Borja y Santa María Magdalena para la iglesia de la Compañía de Jesús (desde 1770, parroquial de San Isidoro el Real) y determina que en las dudas que los ensambladores "tubiesen en las planttas, se haia de estar al dicho del referido d. ${ }^{\mathrm{n}}$ Pedro Rivera, y fenecidos que sean dhos rettablos, se han de reconocer por el suso dho para que vea si esttán arreglados y seg. ${ }^{\mathrm{n}}$ artte". ${ }^{2}$ El retablo de San Francisco de Borja (hoy, de San Ramón nonato), labrado por Manuel Antonio de Pedredo Suárez (h. 1707/1709-Oviedo, 1764), es ligeramente cóncavo y presenta dos columnas de fustes terciados y profusamente entallados inspiradas en el caprichoso repertorio de la Architectvra (1593-1594 y 1598) de Wendel Dietterlin (Pullendorf, Baden-Wurtemberg, 1550/1551-Estrasburgo, 1599), detalle que aclara la sintonía de Rivera con la inventiva bizarra dieciochista. ${ }^{63}$ Frontero a él, el de Santa María Magdalena (hoy, de Nuestra Señora de Lourdes) lo construyó Pedro Álvarez Perera (San Claudio, Oviedo, h. 1692-Oviedo, 1753): también es levemente cóncavo y cuenta dos estípites flanqueando la gruta de la penitente [figs. 2 y 3 ].

\footnotetext{
${ }^{56}$ Quintanal, 1983: 231 y 233. Ramallo, 1985: 43-44 y 544.

57 Para este teatro, García-Valdés, 1991. En los Acuerdos del Ayuntamiento de Oviedo (su titular) de los años 17381740 (Archivo Municipal de Oviedo: A-60 y A-61) no hay referencias a Rivera.

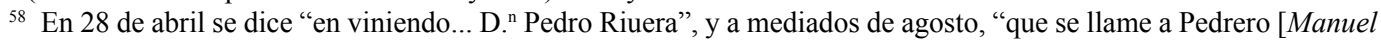
de Pedredo ¿el Mozo?] y á D. " Pedro Rivera”. Cabildos de 28-IV y 14-VIII-1741, Aco: Acuerdos capitulares, 51, ff. 28r y $53 \mathrm{v}-54 \mathrm{r}$.

59 Cabildos de 1-XII-1747 y 12-II-1748, Aco: Acuerdos capitulares, 53, ff. 144v y 157r. En mayo de 1747, Rivera estaba en Oviedo (Cabildo de 16-V-1747, ACO: Acuerdos capitulares, 53, f. 108r).

${ }^{60}$ Cabildos de 31-VII y 7-VIII-1747, ACO: Acuerdos capitulares, 53, ff. 125v y 126r. Se concluyó en 1748 . La construcción del segundo órgano (del evangelio o pequeño) se ordenó en 1749 y acabó en 1751; su dorado se concertó en agosto de 1750 (AHA: caja 7851, ff. 185-186v y 187-188r). Uno y otro, más un realejo (1748, 1749 y 1751; contratados en 1747 y desmantelados en 1902) eran del organero Pedro Echevarría Alcázar († 1771). Miguel Vigil, 1887: 26 y 611612. Quintanal, 1983: 230-248. Ramallo, 1985: 430-433; 1991: 152-154, n. ${ }^{\circ}$ 112; 1999: 216-217. González Santos, 2009 : 232-237, cats. E49-E53 y E88.

${ }^{61}$ Oviedo, 6-I y 28-II-1749, AHA: caja 7771, ff. 709rv, 713v-714r y 748v.

${ }^{62}$ Oviedo, 10-VI-1749, AHA: caja 7923, ff. 157-159. Lo publicó García Sánchez, 1992: 463-464. Hubo una nueva estimación del presupuesto por José Bernardo de la Meana (Oviedo, 25-VI-1749, AHA: caja 7897, f. 200). Ramallo, 1985: 395, 397 y 427-428, fig. 313; 1991: 143, n. ${ }^{\circ} 101$. García Sánchez, 1992: 464-465.

${ }^{63}$ Dietterlin, 1593-1594 y 1598. Ceán, 1816/1921: 292-298.
} 


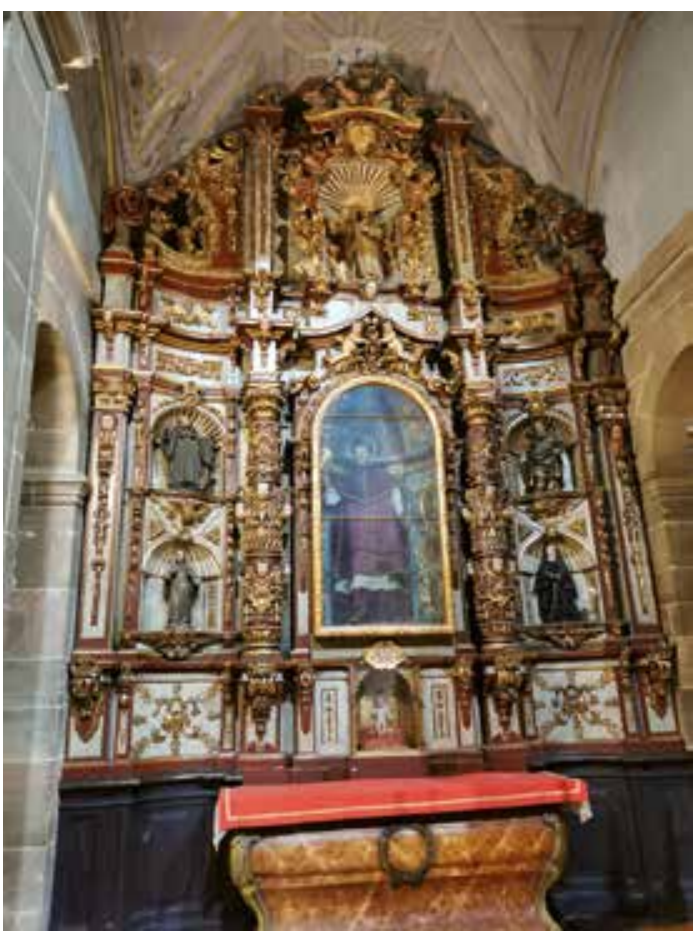

Fig. 2. Pedro González Rivera y Manuel de Pedredo, retablo de San Francisco de Borja (hoy, de San Ramón nonato), 1749. Oviedo, San Isidoro el Real.

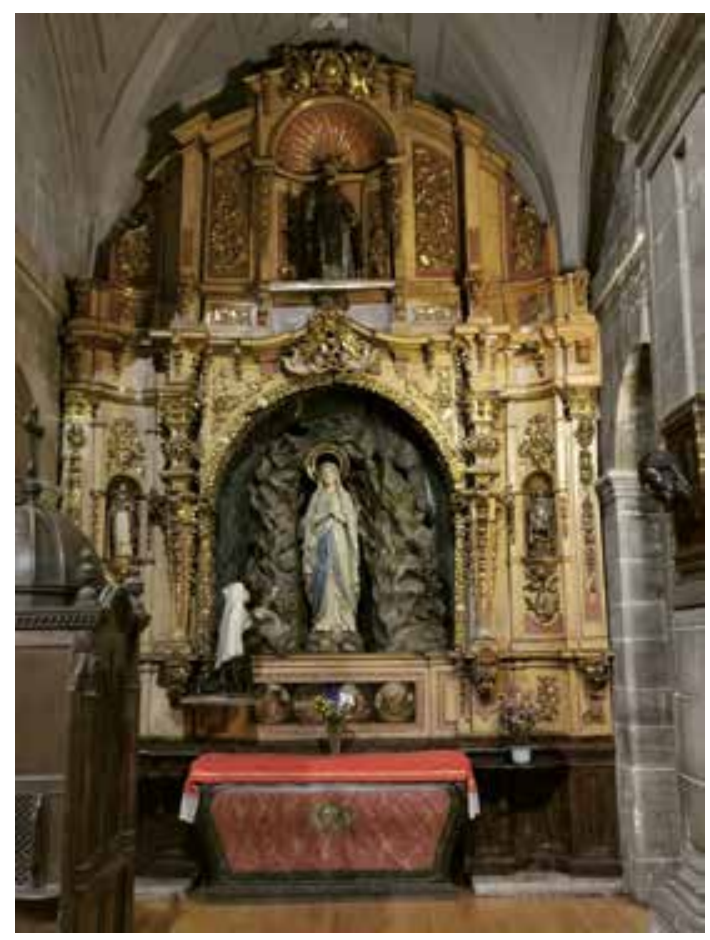

Fig. 3. Pedro González Rivera y Pedro Álvarez Perera, retablo de Santa María Magdalena (hoy, de Nuestra Señora de Lourdes), 1749. Oviedo, San Isidoro el Real.

\section{Un monumento de tramoya}

A mediados de mayo de 1739 el cabildo ya tenía "vn modelo" hecho por Rivera a partir del diseño de Ortega, "muy arreglado y con primor... que á todos los que le vieron gustó mucho, de que se deja conozer su habilidad", por lo que confiaba "que hará el Monumento a satisfación". En vista de lo cual, decidieron pedirle un presupuesto. ${ }^{64}$ Lo que Rivera presentó no fue un nuevo proyecto, sino una muestra con el desarrollo de una de las dos ideas planteadas en el original o parte de ellas [figs. 1 y 7], acomodada a los designios del cabildo, y un desglose que permitiera poner en pie la delineación del pintor madrileño. Este "modelo" de aparejador no se conservó ni se tiene constancia de que perdurara más allá del momento de construcción. Pero qué se llegó a levantar del original de Francisco Ortega no lo sabemos, porque tampoco se conocen testimonios gráficos del aspecto definitivo del monumento.

Antes del mes, la catedral ya tenía la respuesta de Rivera: que sería "obra de quatro messes de trabajo para tres oficiales la pintura" y que "haciendo el cómputo del importe desto" con el coste de materiales "y el agasajo que a él se le há de dar... no parece pueda subir mucho". Como además daba la casualidad de que el deán Juan Fernández Arango y el canónigo Joaquín de Velarde salían para París, Londres y Ámsterdam, se ofrecieron a traer colores y gasa para los transparentes. ${ }^{65} \mathrm{El}$ 12 de junio, por fin, se tomó el acuerdo de hacer el monumento, porque "tendrá mucha conveniencia á la fábrica el que le ejecute don Pedro Rivera", ${ }^{66}$ y el 25 de agosto los trabajos iban tan adelantados que ya se precisaban los colores prometidos por el deán y Velarde, pero que al demorarse en su viaje, "podían acaso no venir a tiempo". Así que se tuvieron que pedir a Madrid. ${ }^{67}$

${ }_{64}^{64}$ Cabildo de 14-V-1739, ACO: Acuerdos capitulares, 50, f. 246v. Ramallo, 1985: 43, nota 7; 1999: 214, nota 102.

${ }^{65}$ Cabildo de 5-VI-1739, ACO: Acuerdos capitulares, 50, f. 249v.

${ }_{66}$ Cabildo de 12-VI-1739, ACO: Acuerdos capitulares, 50, f. 251r. Ramallo, 1999: 214, nota 102.

${ }^{67}$ Cabildo de 25-VIII-1739, ACO: Acuerdos capitulares, 50, f. $269 \mathrm{r}$. 
No hay detalles del transcurso de las obras y de esa fecha saltamos al 30 de abril de 1740, en la segunda semana de Pascua, cuando se constata que el monumento había sido consagrado el Jueves Santo, 14 de abril último, "tan á gusto y satisfacción de todos como VS. as experimentaron y vieron". Así que se propuso "determinar la gratificación que se há de dar á don Pedro Rivera" porque "hasta aora, ni de un modo ni de otro, no se le dio cosa alguna" (detalle palmario de que esta no era su profesión), habiendo librado solo el importe de materiales y salarios de los oficiales y pintores. Se acordó que "assí por lo primoroso de la obra como por el mucho trabajo y tiempo que ocupó dicho don Pedro, se le dén seis mill reales de guantes ${ }^{68}$ y vn corte de vestido con aforros", y más si los comisarios lo estimaran. La satisfacción también comprendió al pintor Francisco Martínez Bustamante y a sus hijos (verdaderos artífices del monumento) quienes, a pesar de que "tardaron bastantemente en hacer la obra", obraron bien, de modo que "si no fuera de su mano, nunca tuviera el Monumento mucho lucimiento", y aunque percibieron sus jornales, fueron cortos, "con esperanza de agasajo". ${ }^{69} \mathrm{Y}$ lo mismo con el "oficial que trabajó las maderas... que se llama Manuel", en cuya atención los capitulares estipularon dar a Bustamante quinientos reales y ciento veinte al ensamblador. ${ }^{70}$

Rivera quedó muy agradecido y se brindó a "hacer alguna cosa de gusto para la octava de el Corpus" (23 de junio) de aquel año por poco dinero, "por quitar de allí aquel vejestorio que se pone", dejando claro que "por su trabajo no quería nada". Se le pidió "vn diseño para que se reconozca si es conveniente y de poco costo" ${ }^{71}$ Pero de esta iniciativa no se volvió a tratar. No obstante, se ha querido relacionar con el templete dorado labrado por Meana en 1766 para el retablo mayor del desaparecido templo parroquial de San Isidoro el Real. ${ }^{72}$

En el Libro de fábrica de la catedral consta lo que costó el monumento: 23.945 reales y 28 maravedís, "en que se incluyen los agasajos que mandó el cavildo dar y el importe de las cinco arañas", imprescindibles para el mejor efecto de la tramoya. ${ }^{73}$ Los siguientes asientos contables corresponden al periódico montaje: alrededor de 280 reales por año. Pero los del cuadrienio 17631766 ya anotan ciertos arreglos en la carpintería a cargo de José Bernardo de la Meana, maestro mayor de la catedral, que con el coste de armarlo y desarmarlo ascendieron a 9197 reales y 17 maravedís. ${ }^{74}$

El influjo del monumento catedralicio en Asturias alcanzó hasta 1784, cuando el anciano Antonio Miranda, rememorando su juvenil experiencia madrileña con Juan Delgado, pintó el monumento de perspectiva del templo mayor de Avilés (asimismo desaparecido). ${ }^{75}$

\section{Vicisitudes y postrimerías}

El monumento barroco estuvo en uso ciento sesenta y tres años, bastantes más de aquellos cincuenta y uno que duró el de Ducete o de los setenta y cuatro del de Huici y Cajigal. Ceán Bermúdez, que llegó a verlo durante su juvenil estancia en Oviedo (1762-1764), lo incorporó a la

68 Agasajo o gratificación, DRAE.

69 Bustamante tuvo dos hijos que lo asistieron: Gregorio (Oviedo, 1702-ante 1764), a partir de 1732, y Ventura Fernando Martínez-Bustamante y Fernández Cárcaba (Oviedo, 1706-post 1760), grabador en dulce establecido en Madrid.

70 Cabildo de 30-IV-1740, ACo: Acuerdos capitulares, 50, f. 337v. Ramallo, 1985: 44, nota 7, y 544; 1999: 214, nota 102. Por aquel tiempo había tres tallistas con este nombre: los Pedredo (padre e hijo) y Manuel González Manjoya (Oviedo, 1715-ante 1766); se podría tratar de éste, pues las actas capitulares cuando se refieren a aquellos lo hacen por el apellido (véanse las notas 7, 47 y 62). Todos, en Ramallo, 1985.

71 Cabildo de 30-IV-1740, ACO: Acuerdos capitulares, 50, ff. 337v-338r. Ramallo, 1999: 214, nota 104. Vejestorio significaba cualquier cosa despreciable por muy vieja (Autoridades).

72 Ramallo, 1999: 214b y fig. Aclara el origen Kawamura, 1994: 239-241; 2001: 146, lám. XIV.

73 AHN: Clero, libro 9172, f. 194r.

74 AHN: Clero, libro 9172, ff. 217r, 238r, 277v, 308v, 328r y 347r. Para Meana, Ramallo, 1985: 448 y siguientes, y García Menéndez, 2010.

75 González Santos, 2017. Véase antes, nota 24. 
producción de Francisco Martínez Bustamante (por conservarse el recuerdo de su efectiva intervención) y apunta que se trataba de un "monumento en perspectiva" pintado al temple. ${ }^{76}$

Tras la invasión francesa, se ordenó repararlo a Juan de Pruneda Cañal (Narzana, 1753-Oviedo, 1816), "p. ${ }^{r}$ haverle destruido en parte los enemigos" y para "que en la próxima Semana S. ${ }^{\text {ta }}$ se coloque según costumbre". ${ }^{77} \mathrm{Y}$ de mediados del siglo XIX hay testimonio de las dificultades financieras que suponía su periódica instalación. ${ }^{78}$

Además de la reproducción del dibujo original, corre impresa una descripción editada en 1879. $\mathrm{Su}$ autor, el canónigo Juan de la Cruz Ceruelo de Velasco (Palencia, 1788-Oviedo, 1882), creía que se trataba del construido en 1612. Hasta tal punto se había perdido la memoria del monumento dieciochista que, gracias a la referencia erudita publicada por Risco en 1795, solo prevalecía el recuerdo de aquél. ${ }^{79}$ El monumento de Semana Santa ovetense era

una obra magestuosa y de admirable efecto: segun el plano que se guarda en el Archivo de esta Santa Iglesia, fué mandado hacer por el Obispo D. Juan Alvarez de Caldas, bajo la direccion del Maestro Juan de Uzeta; su estilo ú órden compuesto.

Ocupa todo el brazo del crucero al Norte y se compone de tres grandes arcos de bastidores, que forman una crypta ó bóveda con su testera: y en el centro está la repisa iluminada por rayos, en que se coloca la urna, ó reservatorio del Santísimo.

Su fábrica es de transparentes, pintados al temple, y de colorido tan firme, que apenas ha decaido en dos siglos y medio de existencia.

\section{Medidas}

El primer arco, que hace la fachada, mide 88 piés hasta los ánditos ó corredores: el resto hasta la bóveda se cubre con un telon negro. Los otros arcos guardan la correspondiente proporcion. El mayor tiene de ancho 30 piés, y 28 de fondo desde la capilla del Rey Casto. Nota. Estas medidas se han tomado del Plano segun su escala. ${ }^{80}$

La reseña concreta donde se instalaba y sus dimensiones: 24,5 metros de altura (cota, sin duda, exagerada), 8,35 de anchura y 7,8 de fondo, pero que guardan la proporción de 1:3 que, precisamente, tiene la reproducción del "plano" original al que aludía el canónigo [figs. 1 y 8 ]. ${ }^{81}$ En los muros del triforio del primer tramo del transepto (sobre la nave del evangelio y boca de la girola) aún se conservan las seis grandes armellas metálicas donde anclaban las garruchas que sujetaban los bastidores y bambalinas de aquel "telón negro".

A partir de 1885, el menoscabo era patente; pese a ello, se seguía montando. ${ }^{82}$ Ya era titular de la diócesis el dominico fray Ramón Martínez Vigil (1840-1904), obispo de Oviedo desde 1884 hasta su fallecimiento. El 30 de enero de aquel año, Manuel Montesinos, "pintor decorador y de historia", se ofreció al cabildo para "construir un monumento nuevo de Semana Santa... por siete mil quinientas pesetas ó la restauración del hoy existe [sic] por la de dos mil", oferta desestimada por falta de fondos. ${ }^{83}$ Con todo, a finales de año se recabó la opinión de Ramón Romea y Ezquerra

${ }^{76}$ Ceán, 1800: I, 183; 2016: 451. De 1801 hay una expresiva referencia del montaje (Cabildo de 17-III-1801, ACO: Acuerdos capitulares, 65 , f. $44 \mathrm{v})$.

${ }_{77}$ Cabildo de 5-IV-1813, Aco: Acuerdos capitulares, 67, f. 14rv. Sandoval, 1908: 72. Kawamura, 1994: 242.

78 "Se acordó se ponga el Monumento; y si no llegasen para sus gastos los tres mil quinientos reales que libró el Gobierno, se supla el resto por el Cabildo." Cabildo de 22-III-1849, ACO: Acuerdos capitulares, 73, s/f.

79 Risco, 1795: 143b. En el mismo error incurrió Canella, 1887: 259, nota 1.

${ }^{80}$ Ceruelo, 1879: 20; 1881: 22-23.

${ }^{81}$ El brazo septentrional del transepto mide $10,5 \mathrm{~m}$ de ancho, 8,8 de fondo y unos 20 de alto.

82 “...hallándose en la actualidad muy necesitado de restauración.” (Canella, 1887: 259, nota 1). El Carbayón. Diario asturiano de la mañana, Oviedo, 13-IV-1892, p. 2 d.

${ }^{83}$ Cabildo ordinario de 30-I-1885, ACO: Acuerdos capitulares, 78, ff. 110v-111r. Manuel Montesinos Estellés, pintor y escenógrafo sevillano, trabajó en los teatros de Andalucía y las decoraciones de la visita de Isabel II a Málaga en octubre de 1862. Un cuadro suyo fue premiado en la Exposición de Sevilla de 1858 (Ossorio, 1869: II, 62. Peláez Martín, 1998: 111). 
(Zaragoza, 1830-Oviedo, 1907), profesor de la Academia de San Salvador de Oviedo, en vías de la restauración o no del mismo. ${ }^{84}$ Por último, a mediados de 1903, el terco e intransigente obispo que vino a desgraciar la faz interior de la catedral propuso la sustitución "lo más pronto posible" del monumento, "en vista del deterioro en que se hallaba el antiguo" ${ }^{85}$ para lo cual se abrió un concurso, forzando al cabildo mediante un acuerdo de 7 de julio de 1903. Entre las condiciones requeridas estaba que "el estilo del Monumento será gótico de los siglos XIV á fines del Xv" y que debía ser resuelto antes del 30 de agosto, dejando a determinación del arquitecto diocesano la aprobación y supervisión de su hechura, prevista para la Semana Santa de 1904. ${ }^{86}$ Hubo nueve trabajos,${ }^{87}$ pero el concurso quedó desierto porque, según informaron los arquitectos diocesano, municipal ovetense y provincial, ${ }^{88}$ sobre "no reunir ninguno de los proyectos presentados condiciones para ser aceptado... El Monumento que hace años se coloca en la Catedral es, no solo muy superior en mérito á los proyectos presentados, sinó una verdadera obra de arte muy digna de conservarse, perpetuando al mismo tiempo una tradición tan respetable de la Basílica asturiana". En fin, proponían su reparación porque en Oviedo había "artistas muy estimables y capaces... de restaurar ó reproducir, ayudados del boceto que se conserva". 89

En el archivo de Carlos Canella Muñiz ${ }^{90}$ hay una fotografía de un Monumento gótico [fig. 4]. Está reforzada por un segundo soporte de papel a cuyo dorso, escrito a lápiz, se lee: "Proyecto de monumento $\mid$ para la Catedral de Oviedo $\mid$ Los autores $\mid$ Mediavilla y Gallo". ${ }^{91}$ En realidad, Mediavilla y Gallo no fueron "los autores", como da a entender el letrero, sino un conocido estudio fotográfico madrileño de comienzos del siglo xx (Fotografía Moderna Madrid-Mediavilla y Gallo). Reproduce un dibujo a lápiz negro y carboncillo, de grueso trazo para el fondo y con toques de aguada grisácea, hecho sobre una hoja de papel Canson, cuya filigrana («ANC ${ }^{\mathrm{NE}}$ MANUF ${ }^{\mathrm{RE}}$ CANSON \& MONTGOLFIER VIDALON-LES-ANNONAY») se corresponde con la fecha. No constan las dimensiones del original, aunque las hojas de marca regular de este fabricante eran de unos $332 \times 440$ milímetros. El diseño es un tanto ingenuo, como idea de mueblista y no de arquitecto titulado, y muestra en perspectiva un templete gótico de cuatro caras y perfiles calados, con profusión de figuras y rematado en anacrónico pináculo-candelero cuajado de luminarias; el interior alberga un tabernáculo erigido sobre una pirámide de ocho gradas. Es el único proyecto conocido del concurso de 1903.

Desechada la alternativa de un nuevo altar se optó, como recomendaban los peritos, por la restauración del antiguo, arrumbado en el claustro. De nuevo se requirió la opinión del anciano Ramón Romea, que debía tutelar la intervención del pintor Senén Rivero, uno de los opositores, elegido al efecto. Este se comprometió a "ejecutar toda la obra de refresco, pintura, reposición de telas rotas, y hacer nuevos los bastidores que resultasen inútiles", así como a hacer "un estudio de montaje que facilite en lo sucesivo la colocación del Monumento" por cuatro mil pesetas..$^{92}$ Esta prevención, empero, no fue atendida y la catedral no solo se vio privada del vistoso monumento barroco sino que

${ }^{84}$ Cabildos de 20-XI y 30-XII-1885, ACO: Acuerdos capitulares, 78, ff. 144v y 148rv (Barón, 1989: 13, nota 33).

${ }_{85}$ Cabildo extraordinario de 15-VI-1903, ACO: Acuerdos capitulares, 79, f. 323rv.

86 Ángulo de 7-VII-1903, ACO: Acuerdos capitulares, 79, f. 326r. "Anuncio de concurso para un Monumento en la catedral”. En: Boletín Oficial Eclesiástico del Obispado de Oviedo, año XL, t. XXXVIII, n. ${ }^{\circ}$ 14, Oviedo (15-VII-1903), pp. 218-220. El arquitecto diocesano (desde 1894, año de su titulación, a 1907) era Luis Bellido González (Logroño, 1869-Madrid, 1955).

${ }^{87}$ Cabildo extraordinario de 4-IX-1903, ACO: Acuerdos capitulares, 79, f. 332r.

${ }^{88}$ Integraron la comisión Luis Bellido, Juan Miguel de la Guardia (Ontaneda, Santander, 1849-Oviedo, 1910) y Nicolás García Rivero (Oviedo, 1853-1923), respectivamente.

${ }^{89}$ Cabildo extraordinario de 9-X-1903, ACO: Acuerdos capitulares, 79, ff. 334v-335r.

${ }^{90}$ Hijo del rector de la Universidad y cronista de Asturias Fermín Canella y Secades (Oviedo, 1849-1924).

${ }^{91}$ Copia por contacto, $167 \times 100 \mathrm{~mm}$ (irregular). Biblioteca de Asturias Ramón Pérez de Ayala, Oviedo: Depósito de la familia Tolivar Alas-Canella, 3-39 Oviedo bis (21).

${ }_{92}$ Cabildo de 16-X-1903, Aco: Acuerdos capitulares, 79, ff. 335v-336r (Barón, 1989: 11, nota 25). El pintor-decorador y escenógrafo Senén Rivero González-Rúa (Oviedo, 1874-1946) fue alumno de Romea en la Escuela de Bellas Artes de San Salvador de Oviedo donde en 1894 aspiró a una pensión de estudios de la Diputación Provincial. Su trabajo más conocido son las láminas con la reconstrucción de las pinturas murales de la basílica altomedieval de Santullano (Selgas, 1916/1990: 65 y xxI) y de varios monumentos asturianos para la Comisión Provincial de Monumentos de Asturias (datos que debo a la amistad de Francisco Crabiffosse Cuesta). Crabiffosse, 2018: 53. 


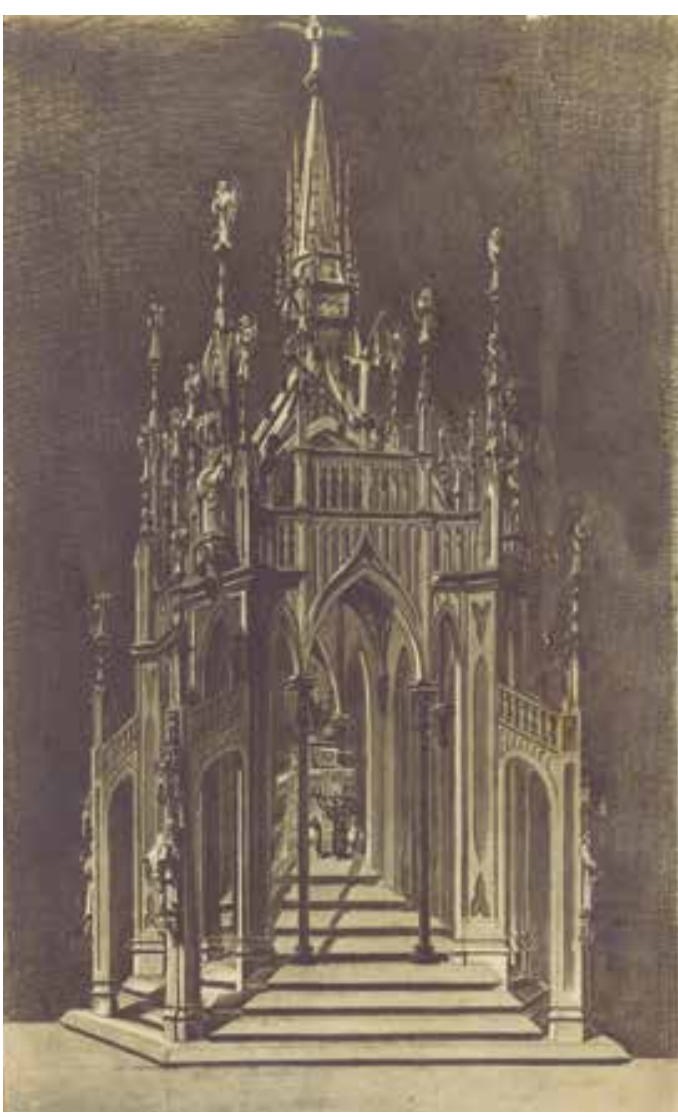

Fig. 4. Proyecto para un monumento gótico en la catedral de Oviedo, 1903. Fotografía de Mediavilla y Gallo (Madrid). Biblioteca de Asturias.

entre 1901 y 1903 experimentó otras transformaciones radicales que dieron a la basílica ovetense su falseado aspecto de templo gótico ideal y abrieron camino para las reformas acometidas en otras catedrales españolas que a partir de entonces se verían privadas del genuino coro y su sofisticado mobiliario. ${ }^{93}$

\section{El proyecto de Francisco Ortega a partir de su fotografía}

En 1903, cuando la catedral decidió prescindir de su venerable monumento eucarístico aún conservaba en su archivo el diseño de Francisco Ortega. ${ }^{94}$ Por fortuna, fue fotografiado en 1924 y desde entonces se ignora el paradero de esta importante muestra del ingenio barroco de la escuela madrileña.

En el número 130 de la revista La Estrella del Mar (segunda quincena de abril de 1924, correspondiente a la Semana Santa) se reprodujo el dibujo original del Monumento del Jueves Santo de la catedral de Oviedo. ${ }^{95}$ Esta ilustración no acompaña un trabajo académico, sino un poema, ¡Divina pasión!, lánguida evocación de las funciones del Jueves Santo vividas por Adolfo de Sandoval en su juventud: "En el amplio crucero o en el trascoro, $\mid$ - del alarife medieval, portento,- $-\mid$ se yergue el ostentoso monumento, | resplandeciente cual un ascua de oro..." y así hasta veintidós cuartetas de indigesta y afectada lírica [figs. 1 y 5$].{ }^{96}$

Adolfo Francisco de Sandoval y García Abellán (Oviedo, 1860-Madrid, 1945), "enamorado de lo tradicional, de ideología católica, de lírica pluma", fue un fecundo novelista de género histórico e inspiración romántica, con abundantes colaboraciones en la prensa católica del momento. Formado en las Universidades de Oviedo (Derecho) y Madrid (Filosofía y Letras y Escuela Superior Diplomática), fue facultativo del cuerpo de Archivos, Bibliotecas y Museos y vivió en Ávila, Madrid y Toledo, de cuya Academia de Bellas Artes y Ciencias Históricas fue correspondiente (por la provincia de Madrid) a partir de 1924-1925. Desde junio de 1883 lo era de la Real de San Fernando por la de Oviedo. Estuvo casado con Elena Oleo, sobrina del historiador menorquín José María Quadrado. ${ }^{97}$ Asimismo, cultivó la música (como compositor e intérprete de piano), el dibujo y la acuarela. Esta afición se deja ver en varias de las viñetas que ilustran sus colaboraciones en La Estrella del Mar de aquel año, recuerdos piadosos de su infancia y juventud. ${ }^{98}$ La otra imagen de ;Divina pasión! es Interior

93 Kraus, 1984: 31-97. Navascués, 1998: 122 y siguientes. Madrid, 1999: 240-254.

94 Cabildo extraordinario de 9-X-1903, ACO: Acuerdos capitulares, 79, f. 334v.

95 Revista de la Confederación Mariana Española, editada por la Compañía de Jesús y vinculada a la congregación madrileña de los Luises: nacida en 1920, hasta 1934 tuvo periodicidad quincenal y desde 1935 a 1962, mensual (Palau, 1951: 195, ords. 84576 y 84577).

96 Sandoval, 1924.

97 Suárez, 1959: vII, 69-74. La necrología, en $A B C$, Madrid, 3-I-1945: 12.

98 Núms. 124 (8-I-1924, pp. 13-14), "Los Reyes pasan..."; "La romería de La Candelaria (recuerdos de la vida estudiantil)", 126 (8-II-1924, pp. 80-81), y “Hacia lo alto (evocación religiosa)”, 129 (24-III-1924, pp. 174-175). 


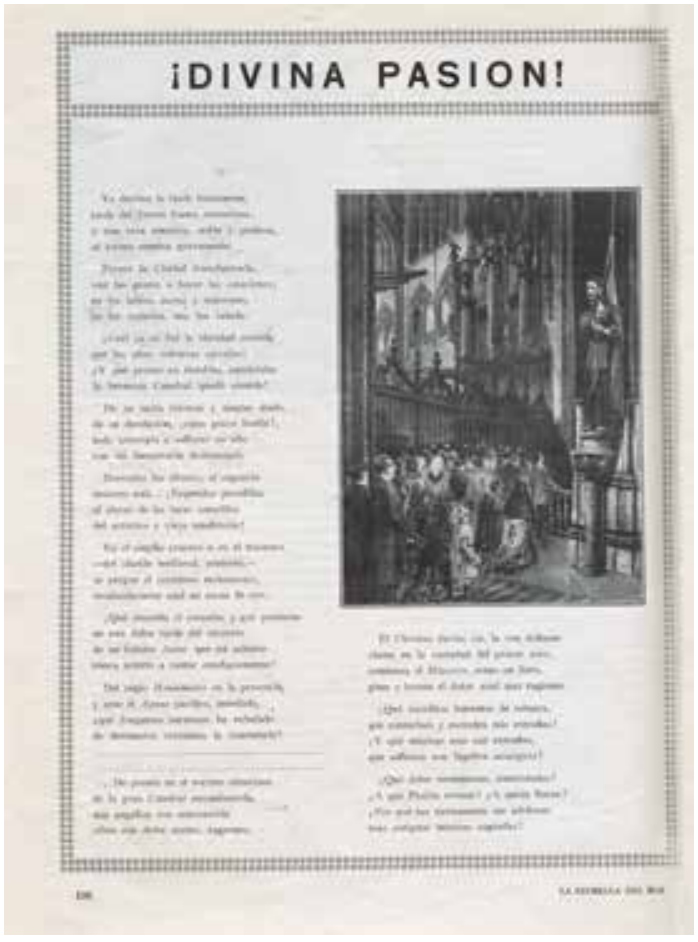

Fig. 5. Adolfo de Sandoval, primera plana de ;Divina pasión! En La Estrella del Mar (1924, p. 196).

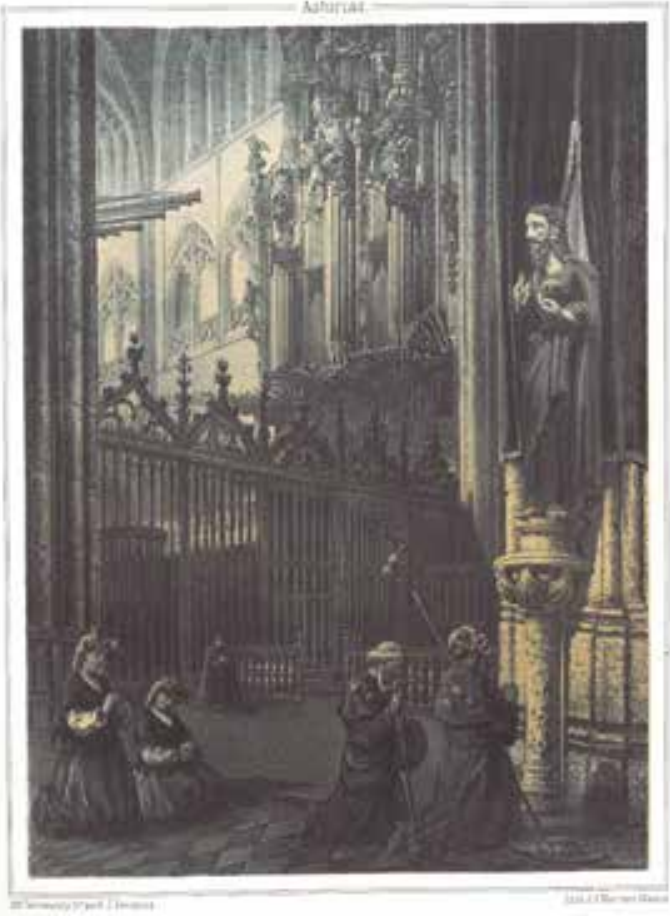

Fig. 6. F. J. Parcerisa (diseño y litografía), Interior de la catedral de Oviedo, 1855. En J. M. ${ }^{\mathrm{a}}$ Quadrado: Recuerdos y bellezas de España. Asturias y León. Madrid: 1855, p. 128 (Biblioteca de la Universidad de Oviedo).

de la catedral de Oviedo desde el crucero, una copia de la conocida litografía de Francisco Javier Parcerisa de 1855 (estampa, $295 \times 200 \mathrm{~mm}$ ) que Sandoval teatralizó añadiendo un grupo de fieles que desde el crucero contemplan el monumento erigido enfrente [figs. 5 y 6 ].$^{99}$

Su hermano Arturo de Sandoval (Oviedo, 1864-1941), ordenado de sacerdote en 1887, fue archivero de la catedral de Oviedo entre 1895 y 1929, correspondiente de la Academia de San Fernando en enero de 1896 y escritor de temas histórico-artísticos. Cabe pensar que fuera él quien le facilitara la vistosa traza de Ortega Delgado de 1732 para ilustrar el poema. En fin, es probable que a raíz de ello el dibujo ya no fuera restituido al Archivo Capitular.

\section{El diseño original}

La invención de Francisco Ortega de 1732, a vista de su reproducción, era de gran calidad técnica y, a lo que parece, de buen tamaño, como aquellos "diseños en grande" 100 de Teodoro Ardemans o José Benito de Churriguera, delineaciones para catafalcos o retablos (alguno de dos varas de alto). ${ }^{101}$ Este tipo de trazas a gran escala ("con bastante magnitud", como dice Terreros)

99 Quadrado, 1855: 128. Sandoval, 1924: 196.

100 Terreros, 1786: 687a.

101 Traza para el túmulo de Carlos II, $1700(730 \times 447 \mathrm{~mm}$. Museo del Prado: D6381). Proyecto para un retablo de la Transfiguración $(1532 \times 725$ mm. Biblioteca Nacional de España: Dib/15/85/82). Retablos de San Francisco de Regis, $1719(1060 \times 520 \mathrm{~mm})$, Virgen de la Merced, $1716(1450 \times 590 \mathrm{~mm})$ y San Basilio Magno, $1717(1610 \times 690 \mathrm{~mm})$, ARABASF: D2384, D2385 y D2386. Otro monumento español, un poco anterior al ovetense, es el de un dibujo del Prado (526 × 272 mm. D3905. Pérez Sánchez, 1989: 51-53). 
fueron corrientes entonces. Además, es probable que el papel estuviera recortado, sin márgenes (reforzado, incluso) y que, en efecto, tuviera el perfil ojival que muestra el fotograbado, adaptado a la flecha de la bóveda gótica de la catedral [figs. 1 y 8].

La reproducción de La Estrella del Mar (asimismo grande: $235 \times 84 \mathrm{~mm}$ ) permite apreciar algunas particularidades del soporte y estado de conservación, así como detalles de concepción, diseño e iconografía. Entre los deterioros, se advierten arrugas y un rasgón en ángulo por la parte derecha del arco apuntado, y sendas dobleces muy marcadas en el tercio inferior y superior, evidencias del vicioso plegado del papel. De igual manera, se reconoce que era un dibujo a tinta, muy pictórico, con sus efectos de color y los contornos trazados a pluma (acaso sobre rasguños de lápiz), y realzado con toques de pincel y aguadas de gamas azuladas (en los celajes, gloria y sahumerios; detalles figurativos y guirnaldas) y grises para contrahacer los jaspeados de molduras, columnas y cajeado de las pilastras. Por lo demás, carece de firma, pitipié y rótulos.

Representaba dos ideas simultáneas, simétricamente dispuestas a lo largo del eje axial: la del lado izquierdo es la más suntuosa, por el mayor número de figuras, con una bóveda de artesa en el bastidor central [fig. 7, en amarillo], que coincide con lo que se podría entender como el crucero de su fingida fábrica, y una cúpula diáfana ovo-semicircular levantada sobre pechinas en la versión alternativa. Confrontaba el orden corintio (a la izquierda) con el compuesto, con mútulos en el friso (derecha), más visibles en el bastidor frontal. En suma, se diferenciaban bien los "tres grandes arcos de bastidores" señalados por Ceruelo de Velasco en 1879.

De gran interés por su situación y tamaño es la composición del edículo superior donde, también en oblicuo, con un acusado punto de fuga muy bajo, distinguimos a Dios Padre, con su pompa celestial, y a Cristo descendiendo la escalinata de un pretorio cubierto por una cúpula nervada, al pie de la cual le esperan varios hombres armados de fiero aspecto para La imposición de la Cruz, ${ }^{102}$ cuya silueta escorzada y a contraluz vemos a la izquierda: el asunto, de cierta complejidad de figuras, caracteres, afectos y su poco de artificio, sin descuidar los trampantojos (sendos pebeteros al pie de las gradas exhalan sus vapores cubriendo la escena de una sutil neblina), tiene resonancias del barroco decorativo de finales del siglo XvII, por el estilo de José Jiménez Donoso o Claudio Coello. ${ }^{103}$ La escena, como todo el monumento, fue pintada al temple por Francisco Martínez Bustamante (formado en aquella escuela al filo de 1700). Por encima, como tarjeta sobrepuesta a las molduras mixtilíneas del arco de embocadura de este cuerpo, destaca la simbólica composición eucarística del pelícano, mientras la medalla de aspecto arriñonado del arco del primer bastidor representa el Sacrificio de Isaac, motivo del Antiguo Testamento que prefigura la alianza de Dios con los creyentes mediante una ofrenda incruenta, como es la eucaristía. Una pareja de ángeles con las alas desplegadas, en forzado contrapicado y cabalgando sinuosos y enguirnaldados recortes disimétricos de rocallas o molduras con volutas fitomorfas y agallonadas, flanquea la rosca exterior del arco del frontispicio. Por último, sobre la falsa linterna del remate (donde hay un candelero sobre un fondo de estrellas) y por encima de una esfera de fuego destaca la Cruz de los Ángeles, blasón de la catedral y diócesis, como una gloriosa aparición: inequívoco detalle que identifica esta traza con la basílica ovetense.

Otros motivos resultan menos patentes, como las dos estatuas del ático, de sinuosas y alargadas siluetas, airosamente recortadas contra el fingido celaje. La de la izquierda es masculina: tipo de anciano calvo y con poblada barba, en que se podría reconocer a san Pablo o si no, a un patriarca o profeta. La de enfrente es femenina, con el rostro vuelto y desembarazada actitud, con un rótulo delante (ilegible) y un niño o ángel a los pies: parece una alegoría, acaso la Caridad. Por tanto, el proyecto podría haber mostrado dos opciones: a los santos Pedro y Pablo (o dos patriarcas) frente a frente o un emparejamiento de virtudes.

102 Mt 27, 31. Mc 15, 20. Lc 23, 23-25. Jn 19, 16-17.

${ }_{103}$ Confróntese con el cuadro de Pedro Ruiz González (1640-1706) de 1673 (lienzo, $123 \times 83 \mathrm{~cm}$. Museo del Prado: P2807). Agüero, 2017: 208-211, cat. 57. Tenido desde Palomino por borrón para un altar, quizás convenga considerarlo modelo para la escena de un monumento: el acusado efecto perspectivo da pie a ello. 


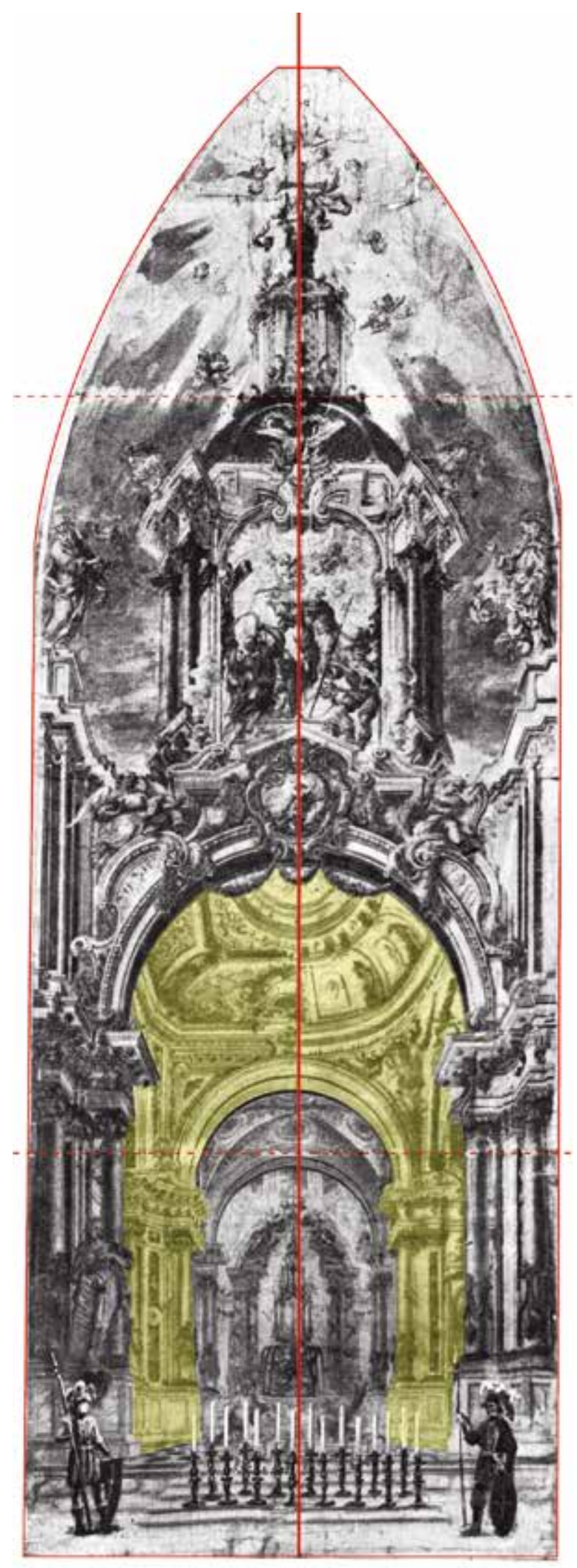

OVIEDU,-Catedral. moeumento del jueves Santo.
Fig. 7. Monumento de la catedral de Oviedo, 1732: identificación de los tres bastidores, eje axial con las dos ideas simultáneas y huellas de plegado a partir de la reproducción de 1924. Diagramación: José Luis Seoane Moro (Universidad de Oviedo) y Olaya García Fernández (Krk Eds.).

Archivo Español de Arte, vol. XCIV, n. ${ }^{\circ}$ 376, pp. 365-386, octubre-diciembre 2021

ISSN: 0004-0428, eISSN: 1988-8511, https://doi.org/10.3989/aearte.2021.21 
En la embocadura del primer bastidor, en la mitad izquierda, se yergue un bulto femenino en afectado contrapposto y declamatorio gesto, cuya mano izquierda acerca al pecho mientras apoya el antebrazo derecho sobre una tabla inscrita con diez renglones, efigie acaso de una sibila, como aquellas que tuvo el monumento concebido por Churriguera para la Encarnación en 1699. ${ }^{104}$ La versión alternativa es solo arquitectónica, con el tercio inferior de los fustes revestido con crespones, moñas y conos de simbología funeral. Las plumadas y siluetas de las figuras trazadas por Ortega recuerdan las de su maestro Ardemans, como las de aquel aparato escénico erróneamente identificado como Apoteosis de san Francisco de Asís y acaso proyectado para la cartuja del Paular. ${ }^{105}$

En el sancta sanctorum ("cripta o bóveda", como la llamó Ceruelo de Velasco), ocupando el área central del punto de fuga de la tramoya se representa una custodia con forma de torre sobre una simbólica fuente con taza (la fons vitae), a cuyo pie se adivinan dos figuras arrodilladas: un ángel en adoración (a la derecha) y una mujer con los brazos abiertos, imagen misma de la Oración o del Alma cristiana, enfrente. Como telón de foro, encuadrando este motivo (que en su periódico montaje sería físico: la urna o la custodia con la forma consagrada), el tercer y último bastidor reproduce un retablo baldaquino rematado con una corona imperial sostenida por ángeles. Recuerda el altar mayor de la cartuja de Granada de Francisco Hurtado Izquierdo (hacia 1710) o el de las Calatravas de Madrid (1720-1724) de José Benito de Churriguera.

Licencia de Adolfo de Sandoval sobreimpresa al diseño original es la doble andana con quince candeleros sobre una grada y los dos soldados con penachos, picas y escudos en primer término, todo de burda hechura y grueso empaste. Los quince cirios son a modo de tenebrario y rememoran el oficio de tinieblas, y los soldados, aquellos que custodiaron el Santo Sepulcro.

La traza (una de aquellas "tramoyas teatrales en los templos" denunciadas por Ceán Bermúdez) ${ }^{106}$ es un acabado modelo de trampantojo y presenta dos rigurosas proyecciones cónicas: la principal corresponde al diseño del buque inferior y está fijada por el acusado enviajado de los dos órdenes del arco de embocadura del primer y segundo bastidor. En el punto de fuga era donde se colocaba la urna o custodia con la forma consagrada para la devoción de las Cuarenta Horas. La otra proyección es la del templete situado encima de la cornisa, cuyas líneas de fuga convergen en las manos maniatadas de Cristo, imagen de la mansedumbre y sacrificio que representa su Pasión.

Este aparato debe mucho a la práctica escenográfica y a ejemplos anteriores, pero también guarda relación con las recomendaciones que Palomino hizo en el apartado "delineación de los Theatros, Altares, y Monumentos de perspectiva" de su tratado. ${ }^{107}$ Palomino copió alguna de las láminas del libro de Andrea Pozzo (1642-1709) y en diferentes lugares acredita haberlo manejado. ${ }^{108}$ También Francisco Ortega tuvo "los dos libros de Poza", heredados de la librería de su maestro Teodoro Ardemans. ${ }^{109}$

\footnotetext{
104 Aterido, 1995: 23 y 27. Cotéjese con la Sibila, dibujo de Angelino Medoro (Roma, 1567-Sevilla, 1633) del Álbum Alcubierre (Navarrete / Pérez Sánchez, 2009, 66-67, cat. 12).

105 Tinta y aguada, $477 \times 324 \mathrm{~mm}$. British Museum: 1846,0509.175. Inequívocamente, se trata de un santo cartujo, pues viste escapulario con capilla. Aterido, 1995-1996: 137, fig. 2. Blasco, 1996-1997: 160. López Conde, 2011: 711-712. McDonald, 2013: 180-181, cat. 49.

${ }^{106}$ Ceán, 1800: Iv, 82 (biografía de Francisco Pérez Sierra); 1816/1921: 290-292. Ceán sabía lo que decía porque se había formado con Juan de Espinal (1714-1783), un consumado quadraturista (1800: II, 32-33).

107 "Pues en los Altares, y Monumentos de perspectiva, como no tienen mutacion, desde luego se ajustan las piezas de vn termino, quedando vnidas vnas con otras... en los quales (ademas de lo inmutable) aún ay la conmodidad de mayor altura, que en los Theatros nos falta, en grave perjuizio de la esbelteza de la Arquitectura, que en ellos se finge, sin poderla encopetar, ni coronar con segundos, ò terceros cuerpos." (Palomino, 1724: libro VIII, capítulo vI, § i, 128; 1947: 621).

108 "De Perspectiva han escrito muchos: ...como lo son los dos [tomos] Modernos de Andrea Poço, tambien Jesuìta, con la Explicacion en Latin, y Toscano, de lo mas peregrino, que en la Practica se hà visto" (Palomino, 1715: 158, 165166, cita, e "Índice de los términos privativos del arte de la pintvra, y svs definiciones etc.", sub voce 'estarcir'; 1724 : "Prólogo", s/p.; 1947: 249a, 257b, $1152 b$ y 426b, respectivamente). Pozzo, 1693: figs. LX-LXVII y LXXII-LXXVII; 1700: figs. XXXVII-XXXVIII y XLII. Bonet, 1973. El prestigio de Pozzo entre los artistas españoles a lo largo del siglo XVIII lo señalan Soler, 2000: 93, y Quiles: 2018.

109 El testamento de Ardemans fue otorgado en Madrid el 2 de mayo de 1722 (Saltillo, 1948: 84. Aterido, 2015a: 210). Francisco Ortega tasó su colección de pinturas en marzo de 1726 (Aterido, 2015a: 31). Los dos tomos de la "Pres-
} 


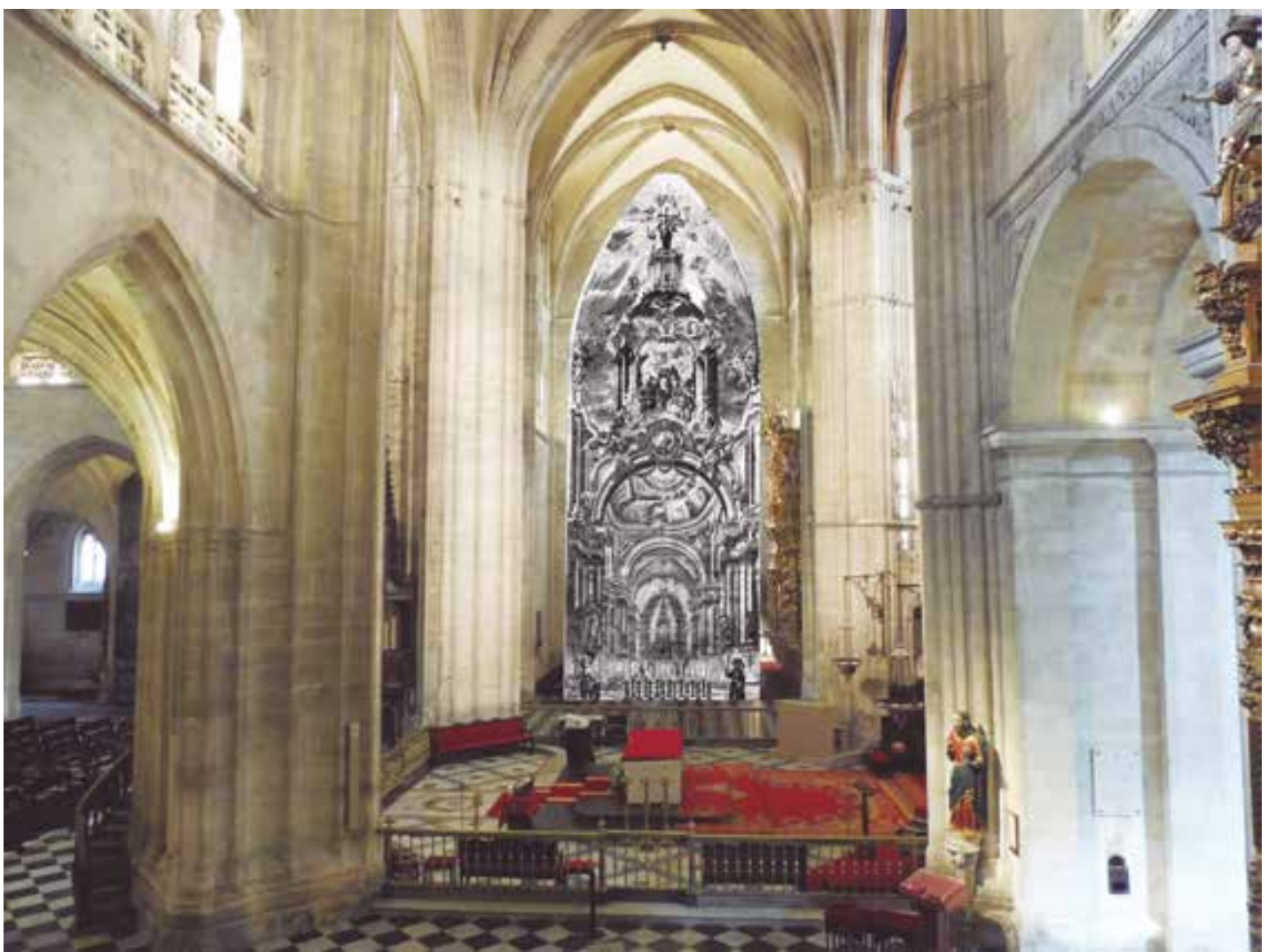

Fig. 8. Apariencia del montaje del Monumento (sobreimpresión de la reproducción del diseño sobre una fotografía actual). Tratamiento de imágenes: Olaya García Fernández (Krk Eds.).

Como su espectacular diseño demuestra, el efecto del monumento ovetense debió ser admirable [fig. 8] porque, como el de aquel tabernáculo ideado por Pozzo para la adoración de las Cuarenta Horas, "ingannerà qui lo rimira e parerà di rilievo". ${ }^{110}$ En ese concepto estaban los arquitectos designados por el cabildo en 1903 que con excelente criterio se manifestaron en contra de su reemplazo.

\section{BIBLIOGRAFÍA}

Agüero Carnerero, Cristina (2017): Carreño de Miranda dibujos. Madrid: Biblioteca Nacional de España y Centro de Estudios Europa Hispánica.

Agulló Cobo, Mercedes (1977): "La biblioteca de don Teodoro Ardemans". En: Simón Díaz, José (dir.): Primeras Jornadas de Bibliografia. Madrid: Fundación Universitaria Española, pp. 571-582.

Agulló y Cobo, Mercedes (1981): Más noticias sobre pintores madrileños de los siglos XVI al XVIII. Madrid: Ayuntamiento de Madrid.

Agulló y Cobo, Mercedes (1994 y 1996): Documentos para la historia de la Pintura española, I y II. Madrid: Museo del Prado.

pectiua del Padre Poza" fueron apreciados en 240 reales. Aparte de este y relacionados con el ilusionismo arquitectónico, Ardemans reunió ejemplares de L'architettura Civile preparata sú la Geometria, e ridotta alle Prospettive de Ferdinando Galli Bibiena (Parma, 1711), la Architectvra de Wendel Dietterlin (1593-1594 y 1598), unas "Mutaziones de comedias francesas", las Variae Architecturae formae de Hans Vredeman de Vries (1601) y otros. Agulló, 1977: 573 y 577. Blasco, 1994: 77b, 78ab, 84b y 93-94; 1996-1997: 156-157 y 160. Aterido, 2015: 248-249.

110 Pozzo, 1693: fig. LX. 
Aterido, Ángel (1995): "Una nueva obra de José de Churriguera: el Monumento de Semana Santa del monasterio de la Encarnación”. En: Anales del Instituto de Estudios Madrileños, xxxv, Madrid, pp. 19-31.

Aterido, Ángel (1995-1996): “Teodoro Ardemans, pintor”. En: Anuario del Departamento de Historia y Teoría de Arte, vol. VII-VIII, Madrid, Universidad Autónoma de Madrid, pp. 133-148.

Aterido, Ángel (2015): El final del Siglo de Oro: la pintura en Madrid en el cambio dinástico, 1685-1726. Madrid: CSIC y Coll \& Cortés.

Aterido, Ángel (2015a): Cronobiografias [CD]. El final del Siglo de Oro: la pintura en Madrid en el cambio dinástico, 1685-1726. Madrid: CSIC y Coll \& Cortés.

Autoridades (1734): Diccionario de la lengua castellana, en que se explica el verdadero sentido de las voces... Tomo quarto. Madrid: Imprenta de la Real Academia Española, por los herederos de Francisco del Hierro.

Barón Thaidigsmann, Javier (1989): Ramón Romea y Ezquerra (1830-1907), pintor y profesor de la Escuela de Bellas Artes de Oviedo. Oviedo: Museo de Bellas Artes de Asturias.

Barrio Moya, José L. (1997): "Francisco Ortega: un pintor giennense en el Madrid de Felipe V”. En: Boletín del Instituto de Estudios Giennenses, 166, Jaén, pp. 101-137.

Barrio Moya, José L. (2000): “Aportaciones a la obra del pintor Francisco Ortega”. En: Boletín del Instituto de Estudios Giennenses, 176, Jaén, pp. 519-527.

Barrio Moya, José L. (2003): "Una Santa Teresa de Jesús, de Juan Delgado en el Oratorio de San Felipe Neri en Alcalá en Henares y algunas noticias sobre su autor”. En: Anales Complutenses, 15, Alcalá de Henares, pp. 75-109.

Barrio Moya, José L. / Martín, Fernando A. (1981): "Un Monumento de Semana Santa para la Real Capilla de Palacio". En: Reales Sitios, XVIII, 70, Madrid, pp. 11-16.

Bassegoda y Hugas, Bonaventura (2004): “Antonio Palomino y la memoria histórica de los artistas en España”. En: Checa, Fernando (dir.): Arte barroco e ideal clásico. Aspectos del arte cortesano de la segunda mitad del siglo XVII. Madrid: Sociedad Estatal para la Acción Cultural Exterior, pp. 89-113.

Blasco Esquivias, Beatriz (1994 y 1996-1997): "Una biblioteca «modélica». La formación libresca de Teodoro Ardemans (I y II)”. En: Ars longa, 5 y 7-8, Valencia, pp. 73-97 y 155-175.

Blasco Esquivias, Beatriz (2013): "Teodoro Ardemans, pintor, arquitecto y tratadista: la mantisa de los más insignes arquitectos”. En: Rodríguez G. de Ceballos, Alfonso (dir.), y Rodríguez Rebollo, Ángel (coord.): Carlos II y el arte de su tiempo. Madrid: Fundación Universitaria Española, pp. 393-412.

Bonet Correa, Antonio (1962): "Los retablos de la iglesia de las Calatravas de Madrid. José de Churriguera y Juan de Villanueva, padre". En: Archivo Español de Arte, xxxv, 137, Madrid, pp. 21-49.

Bonet Correa, Antonio (1973): "Láminas de El Museo Pictórico y Escala Óptica de Palomino". En: Archivo Español de Arte, XLVI, 182, Madrid, pp. 131-144.

Bottineau, Yves (1986): El arte cortesano en la España de Felipe V (1700-1746). Madrid: Fundación Universitaria Española (1.a ed., Burdeos: 1962).

Canella y Secades, Fermín (1887): El libro de Oviedo. Guía de la ciudad y su concejo. Oviedo: Imp. de Vicente Brid (reed.: Obras completas, II. Oviedo, a cargo de Florencio Friera Suárez. Oviedo: Krk, 2011).

Ceán Bermúdez, Juan A. (1800): Diccionario histórico de los más ilustres profesores de las Bellas Artes en España. Compuesto por D. ... y publicado por la Real Academia de S. Fernando. Madrid: Imprenta de la Viuda de Ibarra, 6 vols.

Ceán Bermúdez, Juan A. (1816/1921): "El churriguerismo. (Discurso inédito de D. Juan Agustín Ceán Bermúdez)” [leído en la Academia de la Historia, el 15-XI-1816]. En: Boletín de la Biblioteca Menéndez y Pelayo, III, 6, Santander, pp. 285-300.

Ceán Bermúdez, Juan A. (1829): “Adiciones” a Llaguno y Amírola, Eugenio: Noticias de los arquitectos y arquitectura de España desde su restauración etc. Madrid: Imprenta Real, t. IV.

Ceán Bermúdez, Juan A. (2016): Historia del arte de la pintura en España. Edición de García López, David / Crespo Delgado, Daniel. Oviedo: Krk.

[Ceruelo de Velasco, Juan de la Cruz] (1879): Revista histórico-ignográfica de la Santa Iglesia Basílica de Oviedo. Por un antiguo capitular. 2. ${ }^{a}$ edición, corregida y aumentada. Oviedo: Imp. y Lit. de V. Brid (3. ${ }^{\mathrm{a}}$ ed., Oviedo: 1881).

Crabiffosse Cuesta, Francisco (2018): Líneas al vuelo. Ilustración y diseño gráfico en Asturias, 1879-1937. Gijón: Museo Casa Natal de Jovellanos y Muséu del Pueblu d'Asturies.

Dietterlin, Wendel (1593-1594 y 1598): Architectura. Von Außtheilung, Symmetria und Proportion der Fünff Seulen... Das erste Buch. Stuttgart: s. n., 1593. Architectvr von Portalen vnnd Thürgerichten, mancherlen arten. Das annder Buch. Strasburg: Bernhardt Jobin erben, 1594. Architectvra. Von Außtheilung, Symmetria vnd Proportion der Fünff Seulen, und aller darauß volgender Kunst Arbeit, von Fenstern, Caminen... Núremberg: Hubert \& Balthasar Caymox, 1598.

Durán González-Meneses, Reyes (1980): Catálogo de los dibujos de los siglos XVI y XVII de la colección del Museo de la Casa de la Moneda. Madrid: Fábrica Nacional de Moneda y Timbre.

Fernández Bayton, Gloria (1975): Inventarios reales. Testamentaría del rey Carlos II, 1701-1703. Vol. I. Madrid: Museo del Prado y Patronato Nacional de Museos.

García López, David (2014): "De Palomino a Ceán Bermúdez: la biografía de artistas durante el siglo xvIII". En: Imafronte, 23, Murcia, pp. 103-135.

García Menéndez, Bárbara (2007): "La impronta del escultor Juan de Villanueva y Barbales (1681-1765) en el barroco asturiano del siglo XvIII". En: Liño, 13, Oviedo, pp. 57-68. 
García Menéndez, Bárbara (2008): El escultor y académico Juan de Villanueva y Barbales (1681-1765). Tesis doctoral (inédita). Oviedo: Universidad de Oviedo.

García Menéndez, Bárbara (2009): "El escultor Juan de Villanueva y la colonia de artistas asturianos en el Madrid de la primera mitad del siglo XVIII". En: Liño, 15, Oviedo, pp. 73-82.

García Menéndez, Bárbara (2010): Juan de Villanueva y Barbales, un escultor poleso del siglo XVIII. Pola de Siero (Asturias): IES Escultor Juan de Villanueva.

García Menéndez, Bárbara (2010): “La estancia formativa del escultor, ensamblador y arquitecto asturiano José Bernardo de la Meana en Madrid (h. 1737-1743)". En: Liño, 16, Oviedo, pp. 47-58.

García Menéndez, Bárbara (2011): "Un heresiarca en la Academia. La formación de Diego de Villanueva como escultor y retablista en el entorno del churriguerismo". En: Goya, 337, Madrid, pp. 312-323.

García Sánchez, Justo (1992): Los jesuitas en Asturias. Documentos. Oviedo: Universidad de Oviedo.

García-Valdés, Celsa C. (1991): "La casa de comedias de Oviedo". En: Cuadernos de Teatro Clásico, 6, Madrid, pp. 123-150.

González Santos, Javier (1997): Los comienzos de la escultura naturalista en Asturias (1575-1625). El legado artístico del arzobispo Valdés Salas y el escultor toresano Juan Ducete Diez. Oviedo: Servicio de Publicaciones del Principado de Asturias.

González Santos, Javier (2009): "V. Escultura" y "VI. Pintura”. En: Barón Thaidigsmann, Javier / García de Castro Valdés, César / González Santos, Javier / Hevia Ballina, Agustín / Kawamura, Yayoi / Madrid Álvarez, Vidal de la / Platero Fernández-Candaosa, Ramón / Sanhuesa Fonseca, María (eds.): Museo de la Iglesia de Oviedo: catálogo de sus colecciones. Oviedo: Museo de la Iglesia, pp. 232-237 y 290-294.

González Santos, Javier (2014): "La sillería del coro del desaparecido convento de Santo Tomás de Aquino (Madrid): un trabajo germinal y olvidado de José Benito Churriguera". En: Archivo Español de Arte, LXXXVII, 345, Madrid, pp. 45-64.

González Santos, Javier (2017): “Antonio Miranda García (1710-1786), diletante y coleccionista: anhelos y cuitas de un hidalgo a vueltas entre el mayorazgo y la Academia”. En: Revenga Domínguez, Paula (dir.): Arte barroco y vida cotidiana en el mundo hispánico. II Congreso Internacional. Córdoba: Universidad de Córdoba (en prensa).

González Santos, Javier (2018): "Pintura”. En: Madrid Álvarez (dir.), Vidal de la / Barón Thaidigsmann, Javier / González Santos, Javier / Kawamura, Yayoi / Palacio, Alfonso / Tuñón Escalada, Juan José: Museo de Covadonga. Catálogo de sus colecciones. Madrid: Fundación María Cristina Masaveu Peterson.

González Santos, Javier (2019): "Cosme Bernardo de Palacio: un aficionado y coleccionista de pintura en el funcionariado y pequeña nobleza del siglo xvIII". En: González Ramos, Roberto / Ruiz Carrasco, José María (eds.): Arte y nobleza: el diletantismo artístico en la Edad Moderna. Córdoba: Editorial Universidad de Córdoba, pp. 247-271.

Interián de Ayala, Juan (1730/1782): El pintor christiano, y erudito, ó tratado de los errores que suelen cometerse freqüentemente en pintar, y esculpir las Imágenes Sagradas. Dividido en ocho libros, con un apéndice... Escrita en latín por el M. R. P. M. Fr. ... Y traducida en castellano por D. Luis de Durán y de Bastéro. Madrid: D. Joachín Ibarra, 2 tomos (1. ed. en latín, Madrid: 1730).

Irayzos, Fermín de (1757): Directorio de sacrificantes, instrucción theori-práctica, acerca de las rúbricas generales del Missal, Ceremonias de la Missa Rezada, y Cantada: oficios de Semana Santa, y de otros días especiales del año... Segunda impresión. Madrid: Imprenta, y Librería de Joseph García Lanza.

Jiménez Priego, María Teresa (1982): "Artistas de las reales Caballerizas del Palacio Real de Madrid (pintores, charolistas, ebanistas, doradores y maestros de coches)". En: Anales del Instituto de Estudios Madrileños, xIx, Madrid, pp. 125-150.

Kawamura, Yayoi (1994): "Dos tabernáculos de orden clásico en los siglos XVIII y XIX en Oviedo". En: Los clasicismos en el arte español. Actas del X Congreso del CEHA. Comunicaciones. Madrid: UNED, pp. 239-243.

Kawamura, Yayoi (2001): Festividad del Corpus Christi en Oviedo. La fiesta barroca en su entorno artístico y social en los siglos XVI, XVII y XVIII. Oviedo: Ediciones Nobel.

Kraus, Dorothy / Henry (1984): Las sillerías góticas españolas. Madrid: Alianza Editorial.

Lamas Delgado, Eduardo (2016): "Francisco Rizi: Monumento de Semana Santa de la catedral de Toledo, h. 1668”. En: Navarrete Prieto, Benito (dir.): I segni nel tempo. Dibujos españoles de los Uffizi. Madrid: Fundación Mapfre.

Llaguno y Amírola, Eugenio / Ceán Bermúdez, Juan A. (1829): Noticias de los arquitectos y arquitectura de España desde su restauración. Ilustradas y acrecentadas con notas, adiciones y documentos por etc. Madrid: Imprenta Real, t. IV.

López Alemany, Ignacio / Varey, John E. (2006): El teatro palaciego en Madrid: 1707-1724. Estudio y documentos ("Fuentes para la historia del teatro en España, XXXII"). Woodbridge: Tamesis and Cambridge University Press.

López Conde, Rubén (2011): "Il Teatro delle Quarant'ore. Escenarios de una fiesta italiana en España". En: Camacho Martínez, Rosario / Asenjo Rubio, Eduardo / Calderón Roca, Belén (coords.): Creación artística y mecenazgo en el desarrollo cultural del Mediterráneo en la Edad Moderna. Congreso Internacional. Málaga: Ministerio de Ciencia e Innovación. Universidad de Málaga-Departamento de Historia del Arte, pp. 689-713.

Madrid Álvarez, Vidal de la (1998): El arquitecto barroco Francisco de la Riva Ladrón de Guevara (1686-1741). Gijón: Trea.

Madrid Álvarez, Vidal de la (1999): "La Edad Contemporánea". En: Caso, Francisco de / Cuenca, Cosme / García de Castro, César / Hevia, Jorge / Madrid, Vidal de la / Ramallo, Germán / Tolín, Roberto: La catedral de Oviedo. I. Historia y restauración. Oviedo: Ediciones Nobel, pp. 219-291. 
McDonald, Mark P. (2013): El trazo español en el British Museum: dibujos del Renacimiento a Goya. Madrid: Museo Nacional del Prado.

Miguel Vigil, Ciriaco (1887): Asturias monumental, epigráfica y diplomática. Datos para la historia de la provincia. Texto. Oviedo: Imprenta del Hospicio Provincial.

Montaner López, Emilia (1988): "Pintores de la escuela de Madrid en tierras de Guadalajara". En: Wad-Al-Hayara. Revista de Estudios de Guadalajara, 15, Guadalajara, pp. 387-406.

Navarrete Prieto, Benito / Pérez Sánchez, Alfonso E. (2009): Álbum Alcubierre: dibujos. De la Sevilla ilustrada del conde del Águila a la colección Juan Abelló. Madrid: Fundación Arte Hispánico.

Navascués Palacio, Pedro (1998): Teoría del coro en las catedrales españolas. Discurso del académico electo Excmo. Sr. D. ..., leido en el Acto de su Recepción Pública el día 10 de mayo de 1998, y contestación del Excmo. Sr. D. Fernando Chueca Goitia. Madrid: Real Academia de Bellas Artes de San Fernando.

Nicolau Castro, Juan (1989): "Precisiones documentales sobre el monumento barroco de la catedral de Toledo y un dibujo madrileño del último tercio del siglo XVII". En: Archivo Español de Arte, LXII, 246, Madrid, pp. 216-220.

Ossorio y Bernard, Manuel (1869): Galería biográfica de artistas españoles del siglo XIX. Tomo II. Madrid: Imprenta a cargo de Ramón Moreno.

Palau y Dulcet, Antonio (1951): Manual del librero hispanoamericano, etc. Tomo quinto (E-F). Barcelona: Librería Palau.

Palomino Velasco, Antonio (1715/1947): "Índice de los términos privativos del arte de la pintvra, y svs definiciones etc." En: El Museo pictórico, y escala óptica. Tomo I. Theorica de la pintvra, etc. Madrid: Lucas Antonio de Bedmar, Impressor del Reyno, \&c. (reed. Madrid: M. Aguilar, 1947).

Palomino Velasco, Antonio (1724/1947): El Museo pictórico, y escala óptica. Tomo segundo. Práctica de la pintura, etc. Madrid: Viuda de Juan Garcia Infançon (reed. Madrid: M. Aguilar, 1947).

Palomino Velasco, Antonio (1724a/1947): El Parnaso español pintoresco laureado. Tomo tercero. Con las vidas de los Pintores, y Estatuarios Eminentes Españoles, etc. Madrid (reed. Madrid: M. Aguilar, 1947).

Peláez Martín, Andrés (1998): “El teatro del siglo XIX, modelo para la pintura costumbrista”. En: Álvarez Barrientos, Joaquín / Romero Ferrer, Alberto (eds.): Costumbrismo andaluz. Sevilla: Universidad de Sevilla, pp. 107-124.

Pérez Sánchez, Alfonso E. (1985): “Algunos pintores «rezagados» en el Madrid de Felipe V”. En: Archivo Español de Arte, LVIII, 231, Madrid, pp. 209-229.

Pérez Sánchez, Alfonso E. (1989): “Dos dibujos «churriguerescos» en el Prado”. En: Boletín del Museo del Prado, x, 28, Madrid, pp. 49-53.

Pérez Sánchez, Alfonso E. (2010): Pintura barroca en España (1600-1750). Edición actualizada por Benito Navarrete Prieto. Madrid: Ediciones Cátedra (1. a ed., Madrid: 1992).

Ponz, Antonio (1776): Viage de España, etc. Tomo quinto. Trata de Madrid. Madrid: D. Joachín Ibarra.

Pozzo, Andrea (1693 y 1700): Perspectiva pictorum et architectorum. Pars Prima. Romae: MDCXCIII. Pars secunda. Romae: MDCC.

Quadrado, José M. a (1855): Recuerdos y bellezas de España. Asturias y León. Madrid: Imprenta de Repullés.

Quiles García, Fernando (2018): "Bóvedas celestes y de más colores. El patrón de Pozzo en la cuadratura sevillana”. En: Almansa Moreno, José Manuel / Martínez Jiménez, Nuria / Quiles García, Fernando (eds.): Pintura mural en la Edad Moderna entre Andalucía e Iberoamérica. Sevilla: Universidad Pablo de Olavide, pp. 106-131.

Quintanal, Inmaculada (1983): La música en la catedral de Oviedo en el siglo XVIII. Oviedo: Centro de Estudios del Siglo XVIII y Consejería de Educación y Cultura del Principado de Asturias.

Ramallo Asensio, Germán (1983): Luis Fernández de la Vega, escultor asturiano del siglo XVII. Oviedo: Comisión Diocesana del Patrimonio Artístico-Religioso y Documental y Consejería de Educación y Cultura del Principado de Asturias.

Ramallo Asensio, Germán (1985): Escultura barroca en Asturias. Oviedo: Instituto de Estudios Asturianos.

Ramallo Asensio, Germán (1991): Documentos para el estudio de la escultura barroca en Asturias. Oviedo: Instituto de Estudios Asturianos.

Ramallo Asensio, Germán (1999): "El Barroco". En: Caso, Francisco de / Cuenca, Cosme / García de Castro, César / Hevia, Jorge / Madrid, Vidal de la / Ramallo, Germán / Tolín, Roberto: La catedral de Oviedo. I. Historia y restauración. Oviedo: Ediciones Nobel, pp. 139-217.

Ramallo Asensio, Germán (2011): "Intercambio artístico Asturias-Navarra. El navarro José de Huici Eiturren, sus actividades en la catedral de Oviedo y sus relaciones profesionales con Luis Fernández de la Vega". En: Fernández Gracia, Ricardo (coord.): Pvlchrvm: scripta varia in honorem M. ${ }^{a}$ Concepción García Gainza. Pamplona: Gobierno de Navarra y Universidad de Navarra, pp. 666-673.

Risco, Manuel (1795): España Sagrada. Tomo XXXVIIII. De la Iglesia exenta de Oviedo desde el medio del siglo XIX hasta fines del siglo XVIII. Etc. Madrid: Oficina de la viuda é hijo de Marín.

Saltillo, Marqués del (1948): [Miguel Lasso de la Vega y López de Tejada], "Efemérides artísticas madrileñas (16031811). Conclusión”. En: Boletín de la Sociedad Española de Excursiones, LII, Madrid, pp. 81-120.

Sandoval y Abellán, Adolfo de (1924): “¡Divina pasión!” En: La Estrella del Mar, revista quincenal ilustrada. Órgano de la Confederación Mariana Española, v, 130, Madrid, 16-IV-1924, pp. 196-197.

Sandoval y Abellán, Arturo de (1908): La grandiosa empresa de la Independencia y el Cabildo Catedral de Oviedo. Oviedo.

Selgas, Fortunato de (1916/1990): La basílica de San Julián de los Prados (Santullano) en Oviedo. Estudio de las restauraciones efectuadas en 1912-1915. Madrid: Fototipia de Hauser y Menet (reed. facsimilar, Oviedo: Alvízoras 
Llibros, 1990, con un prólogo de Manzanares Rodríguez, Joaquín: "Don Fortunato de Selgas y Albuerne y su restauración de Santullano de los Prados", pp. VII-XLV).

Simón Díaz, José (1947): "Palomino y otros tasadores oficiales de pinturas". En: Archivo Español de Arte, xx, 78, Madrid, pp. 121-128.

Soler i Fabregat, Ramon (2000): El libro de arte en España durante la Edad Moderna. Gijón: Trea.

Suárez, Constantino (1959): Escritores y artistas asturianos. Índice bio-bibliográfico. Tomo VII. Edición, adiciones y epílogo de José María Martínez Cachero. Oviedo: Instituto de Estudios Asturianos.

Terreros y Pando, Esteban de (1786 y 1788): Diccionario castellano con las voces de ciencias y artes y sus correspondientes en las tres lenguas francesa, latina é italiana. Tomo primero. Y Tomo tercero. Madrid: Imprenta de la Viuda de Ibarra, Hijos y Compañía.

Úbeda de los Cobos, Andrés (2001): Pensamiento artístico español del siglo XVIII: de Antonio Palomino a Francisco Goya. Madrid: Museo Nacional del Prado.

Zuazo, Alexandro (1753): Ceremonial, según las reglas del Missal Romano, ilustrado con doctrinas de los authores mas classicos, antiguos, y modernos, methodo de celebrar la missa rezada, y cantada, etc. Salamanca: Imprenta de la Ilustre Cofradía de la Santa Cruz.

Fecha de recepción:12-IV-2021

Fecha de aceptación: 03-VIII-2021 